\title{
Fatal Attraction: Salience, Naïveté, and Sophistication in Experimental "Hide-and-Seek" Games
}

\author{
By VinCENT P. CRAWFORd AND NAGORE IRIBERRI*
}

\begin{abstract}
"Hide-and-seek" games are zero-sum two-person games in which one player wins by matching the other's decision and the other wins by mismatching. Although such games are often played on cultural or geographic "landscapes" that frame decisions nonneutrally, equilibrium ignores such framing. This paper reconsiders the results of experiments by Rubinstein, Tversky, and others whose designs model nonneutral landscapes, in which subjects deviate systematically from equilibrium in response to them. Comparing alternative explanations theoretically and econometrically suggests that the deviations are well explained by a structural nonequilibrium model of initial responses based on "level-k" thinking, suitably adapted to nonneutral landscapes. (JEL C72, C92)
\end{abstract}

Any government wanting to kill an opponent... would not try it at a meeting with government officials.

- Comment on the poisoning of

Ukrainian presidential candidate (now president) Viktor Yushchenko, quoted in C. J. Chivers (2004)

... in Lake Wobegon, the correct answer is usually "c."

- Garrison Keillor (1997) on multiple-

choice tests, quoted in Yigal Attali and

Maya Bar-Hillel (2003)

\footnotetext{
* Crawford: University of California, San Diego, 9500 Gilman Drive, La Jolla, CA 92093 (e-mail: vcrawfor@ dss.ucsd.edu); Iriberri: Departament d'Economia i Empresa, Universitat Pompeu Fabra, Ramon Trias Fargas 2527, 08005 Barcelona, Spain (e-mail: nagore.iriberri@upf. edu). Most of Iriberri's work on this paper was completed at the University of California, San Diego. We are grateful to the National Science Foundation (Crawford), the Centro de Formación del Banco de España (Iriberri), and the Barcelona Economics Program of CREA (Iriberri) for research support; to Miguel Costa-Gomes, Victor Ferreira, Navin Kartik, Barry Nalebuff, Steven Scroggin, Ricardo Serrano-Padial, Joel Sobel, David Swinney, Mark Voorneveld, Mark Walker, Joel Watson, and three anonymous referees for helpful comments or discussions; to Dale Stahl for helpful discussions and for providing a copy of Michael Bacharach and Stahl (1997a); to Stahl and Daniel Zizzo for searching for Bacharach and Stahl (1997b); to Barry O'Neill and Amnon Rapoport (with the help of Ido Erev and Mark Walker, respectively) for providing data from their experiments; and to Ariel Rubinstein for providing a copy of Rubinstein and Amos Tversky (1993), searching for additional data, and helpful discussions. Glenn Close and Michael Douglas (http://www.imdb.com/title/tt0093010/) were no help at all.
}

Game theorists have been intrigued by hideand-seek games-zero-sum two-person games in which one player wins by matching the other's decision and the other wins by mismatching-for more than 50 years (John von Neumann 1953). These games cleanly model a strategic problem that is central to many economic, political, and social settings, as well as the obvious military and security applications. Examples include entry games where entry requires a differentiated product, and blocking it requires matching the entrant's design; election campaigns in which a challenger can win only by campaigning in different areas from those of the incumbent; and fashion games in which hoi polloi wish to mimic the elite but the elite prefer to distinguish themselves.

Although zero-sum two-person games are one of game theory's success stories, equilibrium analysis of hide-and-seek games is not very helpful as a guide to prediction or decision making. There seem to be two main reasons for this, both illustrated by our epigraphs: hide-and-seek games are often played without clear precedents, so equilibrium depends on strategic thinking rather than learning; but such thinking may not follow the fixed-point logic of equilibrium. A game theorist would reply to our first epigraph, "But if investigators thought that way, a meeting with government officials is precisely where a government would try to kill an opponent." Further, hide-and-seek games are usually played on naturally occurring cultural 
or geographic "landscapes" that are nonneutral across locations in framing and/or payoffs. Equilibrium ignores such landscapes except as they affect payoffs, but nonequilibrium thinking may respond to them.

Both reasons are also well illustrated by the experimental results of Rubinstein and Tversky (1993; "RT") and Rubinstein, Tversky, and Dana Heller (1996; "RTH”); see also Rubinstein (1999; "R"). RT, RTH, and R (collectively "RTH") elicited subjects' initial responses to hide-and-seek games. RTH explained the games as "stories," probably increasing subjects' comprehension. In a leading example, $\mathrm{R}$ told seekers: "You and another student are playing the following game: Your opponent has hidden a prize in one of four boxes arranged in a row. The boxes are marked as follows: A, B, A, A. Your goal is, of course, to find the prize. His goal is that you will not find it. You are allowed to open only one box. Which box are you going to open?" Hiders were told an analogous story. Thus, the entire structure, including the order and labeling of locations, was publicly announced. ${ }^{1}$

This story makes the framing of locations nonneutral in two ways. The " $\mathrm{B}$ " location is distinguished by its label, and so is salient in one of Thomas Schelling's (1960) senses. And the two "end A" locations, though not distinguished by their labels, may be inherently salient, as RT and RTH argue, citing Nicholas Christenfeld (1995). As RT note, these two saliencies interact to give the remaining location, "central A," its own brand of uniqueness as "the least salient location." This aspect of their designs is important as a tractable abstract model of a naturally occurring landscape.

Figure 1 translates RTH's story into a payoff matrix. Because the seeker chooses without observing the hider's choice, their choices are strategically simultaneous. If the seeker chooses the same location as the hider, he wins a payoff normalized here to one; if not, the hider wins that payoff. This game has a unique equilibrium

\footnotetext{
${ }^{1}$ RT's and RTH's subjects' payments appeared sufficient to motivate them, and the binary-lottery structure of the payoff function implies under standard assumptions that players maximize expected money payoffs, without regard to risk preferences. Note, however, that in R's experiments, subjects were not paid or screened for exposure to game theory.
}

in mixed strategies, in which both players randomize uniformly across locations, independent of their framing. Because the seeker can choose only one of the four locations, he is at a disadvantage in equilibrium, finding the prize only 25 percent of the time. Despite this clear equilibrium prediction, RTH's publicly announced order and labeling of locations create a potential for framing effects, and their subjects deviated systematically from equilibrium in ways that were highly sensitive to framing. ${ }^{2}$ Table 1 gives the aggregate choice frequencies for the "RTH-4" treatment described above and RTH's most closely related other treatments. (Table A1 in the Web Appendix, available at http://www.e-aer.org/data/ dec07/20050133_app.pdf, gives frequencies from less closely related treatments.) In RTH-4, central A was the strongly modal choice for both hiders and seekers, and was even more prevalent for seekers than hiders. As a result, assuming independence, seekers could expect to find the prize 32 percent of the time, substantially more than the 25 percent equilibrium predicts. These qualitative patterns extend, properly interpreted, to the other five treatments in Table 1, which we shall argue are closely analogous to RTH-4. They also extend with minor exceptions to a very large sample from more recent Internet experiments (Rubinstein, private communication).

Like the beliefs that underlie our epigraphs, these patterns are an intriguing puzzle: If hiders and seekers are equally intelligent, on average, why don't hiders tempted to hide in central A realize that seekers will also be tempted to look there? Why do hiders allow seekers to find

\footnotetext{
${ }^{2}$ The $p$-values from chi-square tests for significant differences from equilibrium in hiders' and seekers' choice frequencies in RTH's six treatments are shown in Table 1. Although in this game any strategy, pure or mixed, is a best response to equilibrium beliefs, systematic deviations of aggregate choice frequencies from equilibrium probabilities must (with high probability) have a cause that is partly common across players, and are therefore indicative of systematic deviations from equilibrium. Other studies of framing effects in different kinds of games include Jörn Scharlemann et al. (2001), who studied trust games in which otherwise anonymous players were "labeled" by photographs; and Judith Mehta, Chris Starmer, and Robert Sugden (1994) and Nicholas Bardsley et al. (2006), who studied coordination games in which decisions had naturally occurring labels, as in Schelling's (1960) classic experiments.
} 


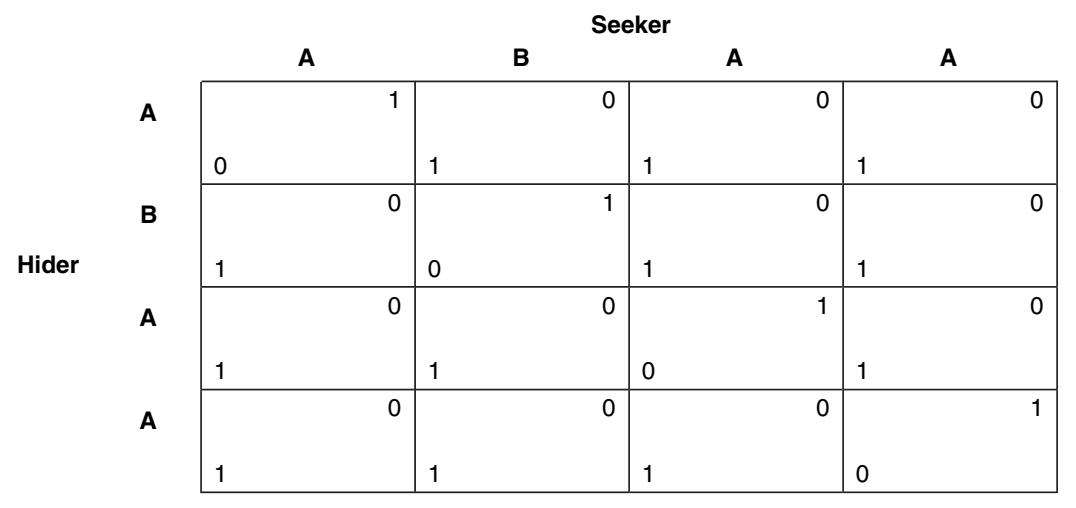

Figure 1. RTH's Hide-AND-SEEK GAME

them 32 percent of the time when they could hold it down to 25 percent via the equilibrium mixed strategy? The puzzle is deepened by the patterns' robust asymmetry across player roles. Why do seekers choose central A more often than hiders? Although the payoff structure is asymmetric, this asymmetry is not explained by noisy generalizations of equilibrium such as Richard McKelvey and Thomas Palfrey's (1995) quantal response equilibrium (QRE), which coincides with equilibrium in RTH's games.

RTH took their subjects' deviations from equilibrium as prima facie evidence that the subjects did not think strategically; and with one exception, explained below, they did not consider alternative explanations of their results. ${ }^{3}$ But in our view, such robust patterns of behavior are unlikely to lack a coherent explanation; and given the simplicity of the strategic question hide-and-seek games pose, the explanation is unlikely to be nonstrategic. On the contrary, deviations from equilibrium in games where its rationale is especially strong seem to offer a particularly promising opportunity to explore

\footnotetext{
${ }^{3}$ In RT's words, "The finding that both choosers and guessers selected the least salient alternative suggests little or no strategic thinking." In RTH's words, “... the players employed a naïve strategy (avoiding the endpoints), that is not guided by valid strategic reasoning. In particular, the hiders in this experiment either did not expect that the seekers too, will tend to avoid the endpoints, or else did not appreciate the strategic consequences of this expectation."
}

alternative strategic theories of initial responses to games.

In this paper we propose an explanation of RTH's and related results using a nonequilibrium model of initial responses to games based on "level- $k$ " thinking, building on Bacharach and Stahl's (1997a) analysis of a simplified version of RTH's games. ${ }^{4}$ Level- $k$ models were introduced by Stahl and Paul Wilson (1994, 1995) and Rosemarie Nagel (1995) and further developed by Teck-Hua Ho, Colin Camerer, and Keith Weigelt (1998), Costa-Gomes, Crawford, and Bruno Broseta (2001), Crawford (2003), Camerer, Ho, and Juin Kuan Chong (2004), CostaGomes and Crawford (2006), and Crawford and Iriberri (2007). They have strong experimental support, which should allay the concern that once one relaxes equilibrium, anything is possible. Like RTH, we focus on hide-and-seek and related games played on landscapes that are nonneutral in the framing of locations but neutral with regard to payoffs. ${ }^{5}$ Although learning may

\footnotetext{
${ }^{4}$ Bacharach and Stahl's (1997a) analysis of hide-andseek games did not appear in the published version of their paper, Bacharach and Stahl (2000). Bacharach and Stahl (1997b), whose title suggests a more detailed version of their hide-and-seek analysis, is no longer available. The relationship between their analysis and ours is explained below.

${ }^{5}$ Robert Rosenthal, Jason Shachat, and Mark Walker (2003), and papers cited therein, report experiments on hide-and-seek games with nonneutral payoffs but neutral framing. Camerer, Ho, and Chong $(2004,883)$ show that level- $k$ models can explain subjects' responses to such
} 
converge to equilibrium over time, we also follow RTH in studying subjects' initial responses, which reveal their strategic thinking most clearly. Our goals are to resolve a long-standing behavioral puzzle; to explore the specification of level- $k$ models for games played on nonneutral landscapes; and to establish a link between RTH's results and experimental work on strategic thinking, and so bring new evidence to bear on modeling initial responses to games.

Our level- $k$ model allows behavior to be heterogeneous, but it assumes that each player follows a rule drawn from a common distribution over a particular hierarchy of decision rules or types. Type $L k$ for $k>0$ anchors its beliefs in a nonstrategic $L O$ type and adjusts them via thought-experiments with iterated best responses: $L 1$ best responds to $L O, L 2$ to $L 1$, and so on. $L 1$ and higher types have accurate models of the game and they are rational in that they choose best responses to beliefs. Their only departure from equilibrium is replacing its assumed perfect model of others' decisions with simplified models that avoid the complexity of equilibrium analysis.

In applications, the population type frequencies are usually estimated from the current dataset or translated from previous work. The estimated distribution tends to be stable across games and hump-shaped, with most weight on $L 1, L 2$, and $L 3$. Thus, the anchoring $L O$ type exists mainly in the minds of higher types. Even so, its specification is the main issue that arises in defining a level- $k$ model for games with nonneutrally framed locations, and the key to its explanatory power.

We show that a level- $k$ model with an $L O$ that is insensitive to payoffs and symmetric across player roles, but sensitive to framing in that $L O$ is constrained to favor salient locations, as seems plausible for a payoff-insensitive anchoring type,

games. Crawford, Uri Gneezy, and Yuval Rottenstreich (2007) propose a level- $k$ explanation along the lines suggested here of coordination experiments in which subjects respond strongly to both labeling and salience created by payoff perturbations, which opposes label salience in one player role but reinforces it in the other. Von Neumann (1953) characterized equilibria in hide-and-seek games whose payoffs vary with location, including a two-dimensional game in which a hider hides in a matrix and a seeker guesses the hider's row or column. allows a simple explanation of RTH's and related results. Estimating the model with population type frequencies and $L O$ 's choice probabilities constrained to be equal across roles yields a type distribution like those previously estimated for other games, though with somewhat more weight on higher types than usual, perhaps due to the transparency of the strategic question hideand-seek games pose. The estimated mixture of types' best responses to such an $L O$ explains subjects' robust, role-asymmetric deviations from equilibrium, with no difference in behavioral assumptions for hiders and seekers.

Although our proposed level- $k$ model yields a plausible resolution of the puzzle posed by RTH's results, its large number of parameters and the freedom to specify $L O$ raise concerns about overfitting within RTH's sample and portability, the extent to which estimating the model for RTH's games helps to predict behavior in other games. We address these concerns by comparing it with four alternatives: two level- $k$ models that relax the constraints that $L O$ favors salience and/or is role-symmetric; and two equilibrium models as close as possible to the mainstream, with "hard-wired" payoff perturbations that can describe an instinctive attraction to salience for seekers and an instinctive aversion for hiders, one with their magnitudes (but not signs) restricted to be the same for hiders and seekers and one with their magnitudes unrestricted. The Web Appendix extends these equilibrium comparisons to QRE with perturbations, which never performs better than equilibrium with perturbations, and sometimes performs worse. The alternative models can also explain RTH's results, usually with a small likelihood advantage over our proposed model. But they, too, have large numbers of parameters, and they raise similar concerns about overfitting and portability.

We test for overfitting within RTH's sample by using each model to compute estimates separately for each of their six treatments and using each estimated model to "predict" the results of the other five treatments. Overall, our proposed level- $k$ model fits slightly worse than all four alternatives. But the proposed model has a lower mean squared prediction error (MSE) than each alternative except the level- $k$ model that relaxes the constraint that $L O$ is role-symmetric, whose error is 10 percent lower. 
Table 1-Aggregate Choice Frequencies in RTH's Treatments

\begin{tabular}{|c|c|c|c|c|}
\hline RTH-4 & A & $B$ & A & A \\
\hline $\operatorname{Hider}(53 ; p=0.0026)$ & 9 percent & 36 percent & 40 percent & 15 percent \\
\hline $\operatorname{Seeker}(62 ; p=0.0003)$ & 13 percent & 31 percent & 45 percent & 11 percent \\
\hline RT-AABA-Treasure & A & $\mathrm{A}$ & $B$ & A \\
\hline $\operatorname{Hider}(189 ; p=0.0096)$ & 22 percent & 35 percent & 19 percent & 25 percent \\
\hline Seeker $(85 ; p=9 \mathrm{E}-07)$ & 13 percent & 51 percent & 21 percent & 15 percent \\
\hline RT-AABA-Mine & A & A & $B$ & A \\
\hline $\operatorname{Hider}(132 ; p=0.0012)$ & 24 percent & 39 percent & 18 percent & 18 percent \\
\hline Seeker $(73 ; p=0.0523)$ & 29 percent & 36 percent & 14 percent & 22 percent \\
\hline RT-1234-Treasure & 1 & 2 & 3 & 4 \\
\hline $\operatorname{Hider}(187 ; p=0.0036)$ & 25 percent & 22 percent & 36 percent & 18 percent \\
\hline $\operatorname{Seeker}(84 ; p=3 \mathrm{E}-05)$ & 20 percent & 18 percent & 48 percent & 14 percent \\
\hline RT-1234-Mine & 1 & 2 & 3 & 4 \\
\hline $\operatorname{Hider}(133 ; p=6 \mathrm{E}-06)$ & 18 percent & 20 percent & 44 percent & 17 percent \\
\hline $\operatorname{Seeker}(72 ; p=0.149)$ & 19 percent & 25 percent & 36 percent & 19 percent \\
\hline R-ABAA & A & B & A & A \\
\hline $\operatorname{Hider}(50 ; p=0.0186)$ & 16 percent & 18 percent & 44 percent & 22 percent \\
\hline $\operatorname{Seeker}(64 ; p=9 \mathrm{E}-07)$ & 16 percent & 19 percent & 54 percent & 11 percent \\
\hline
\end{tabular}

Notes: Sample sizes and $p$-values for significant differences from equilibrium in parentheses; salient labels in italics; order of presentation of locations to subjects as shown.

We evaluate portability by using each model to "predict" subjects' initial responses in Barry O'Neill's (1987) and Amnon Rapoport and Richard Boebel's (1992) experiments, whose games are strategically close to RTH's games but with more complex win-loss patterns, different framing, and in one case five locations. The equilibrium with perturbations models are easily adapted to O'Neill's game using the same general notions of salience as for RTH's games; but in each case the perturbations estimated under the natural constraints regarding how players react to salience are 0 , reducing the model to an equilibrium model, which predicts O'Neill's subjects' initial responses poorly. The level- $k$ models adapt just as easily and predict well. For O'Neill's game our proposed level- $k$ model with a role-symmetric $L O$ that favors salience has lower MSE than any of the alternative models. The level- $k$ models with role-symmetric $L O$ adapt easily to Rapoport and Boebel's more complex game; but there is no plausible, parsimonious way to adapt a model with a roleasymmetric $L O$ or the equilibrium with perturbations models to that game. Our proposed model has total MSE slightly lower than equilibrium or a level- $k$ model with a role-symmetric $L O$ that avoids salience. The analysis traces our proposed model's advantage in portability to its reliance on general principles of strategic behavior that are not overly sensitive to the details of the structure.

The rest of the paper is organized as follows. Section I explains the analogies among RTH's six treatments and the case for pooling their data the way we do. Sections II and III describe our equilibrium with perturbations and level- $k$ models. Section IV reports econometric estimates, Section V discusses overfitting, and Section VI discusses portability. Section VII concludes.

\section{Analogies Across RTH's Treatments}

This section describes the five other RTH treatments in Table 1 and explains the senses in which they are analogous to the RTH-4 treatment. We then argue that, properly interpreted, the patterns of deviations from equilibrium in RTH-4-that central A was modal for both hiders and seekers, and even more prevalent for seekers-extend to the five other treatments. We also test whether the choice frequencies in RTH's six treatments can be pooled in the econometric analysis. 
In RTH-4, the hider hid a desirable "prize," which we call a "treasure" as in RTH (1996). The five other treatments include three more treasure treatments, RT-AABA-Treasure, RT1234-Treasure, and R-ABAA. They also include two "mine" treatments, RT-AABA-Mine and RT-1234-Mine, identical to the corresponding treasure treatments except that the hidden object is undesirable, so that hiders' and seekers' 0-1 payoffs are interchanged. This yields an equivalent normal form with players' roles reversed, leaving equilibrium predictions unchanged.

However, because hiders inherently move first, even though seekers do not observe their choices, mine treatments have different extensive forms than treasure treatments with reversed roles. RTH, suspecting that this difference might make it easier for seekers to mentally simulate hiders' choices, used mine treatments to test whether it explains why seekers in treasure treatments did better than equilibrium predicts. But the mine treatments yielded results very close to the treasure treatments with roles reversed, which suggests that the seekers' advantage was somehow driven by subjects' responses to the normal-form structure, as in all of the models considered here.

In the three ABAA or AABA Treasure treatments and the AABA Mine treatment, central A was modal for both hiders and seekers. This pattern extends to the 1234 Treasure and Mine treatments if we follow RT's suggestion that "the least salient response... may correspond to 3 , or perhaps 2 " and take 2 as analogous to B and 3 to central A. Given this correspondence, central A was more prevalent for seekers in all four treasure treatments and more prevalent for hiders in both mine treatments. Thus, if hiders in treasure and seekers in mine treatments are treated as equivalent, this pattern is also the same in all six treatments. Further, the frequencies with which seekers found a treasure or a mine exceeded 25 percent, so that seekers (hiders) had higher (lower) expected payoffs than in equilibrium in treasure treatments, and vice versa in mine treatments.

From now on, we build in these analogies by treating 2 as equivalent to $\mathrm{B}$, and treating mine treatments as equivalent to treasure treatments with reversed player roles. To avoid unnecessary repetition, we use "central A" to refer to either a central A or a 3 location, and so on; and we refer to mine treatments as if they were treasure treatments with reversed roles. No theory of which we are aware could predict these equivalences across different frames; their justification is that they allow us to use a more general theory of strategic behavior to interpret the patterns in the data.

After transforming the data accordingly, chisquare tests for differences in subjects' aggregate choice frequencies reveal no significant difference for seekers ( $p$-value 0.4836 ) or hiders ( $p$-value 0.1635$)$ across the six treatments. We therefore pool the data, except as noted. The pooled sample includes 624 hiders and 560 seekers, with the aggregate choice frequencies in Table $3 .^{6}$

\section{An Equilibrium with \\ Payoff Perturbations Model of RTH's Games}

To fix ideas, we begin with an explanation of RTH's results as close as possible to the mainstream, an equilibrium model with hardwired payoff perturbations that can describe an instinctive attraction to salience for seekers and an instinctive aversion for hiders. Because the end As' frequencies are almost equal in the data, we set their perturbations equal for simplicity. Thus, we assume that seekers gain an additional payoff of $e$ for an end A location or $f$ for the B location; and we further assume that hiders lose the same payoffs for those choices, yielding the perturbed matrix in Figure 2. Given the signs of the perturbations, intuition suggests that $e, f>$ 0 ; but we do not assume this here.

First, restrict the magnitudes of $e$ and $f$ to be the same for hiders and seekers as in Figure 2. If $-1<(f-2 e),(2 e-3 f),(2 e+f)<3$, the perturbed game has a unique, symmetric, totally mixed equilibrium, with hiders and seekers both playing A, B, A, A with probabilities $1 / 4-e / 2+f / 4,1 / 4+e / 2-3 f / 4,1 / 4+e / 2+f / 4$, and $1 / 4-e / 2+f / 4$. Both hiders and seekers

\footnotetext{
${ }^{6}$ We made minor adjustments to RTH's published data to reconcile reported frequencies and sample sizes (see the Web Appendix). Pairwise tests suggest that RTH-4 has somewhat higher frequencies of B (as well as central A) for both hiders and seekers. Although this difference is intriguing, we focus on explaining the more robust patterns discussed in the text.
} 


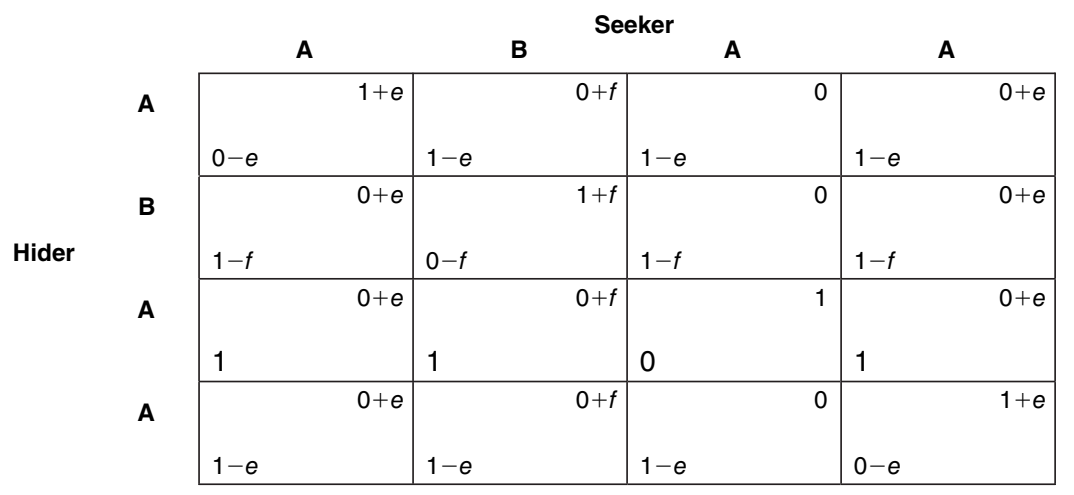

Figure 2. RTH's Hide-And-Seek Game with Payoff Perturbations

play central A with probability $1 / 4+e / 2+f / 4$, which is greater than $1 / 4$ when $2 e+f>0$. A seeker finds the treasure with probability

$$
\text { (1) } \begin{aligned}
& \left(\frac{1}{4}-\frac{e}{2}+\frac{f}{4}\right)^{2}+\left(\frac{1}{4}+\frac{e}{2}-\frac{3 f}{4}\right)^{2} \\
& +\left(\frac{1}{4}+\frac{e}{2}+\frac{f}{4}\right)^{2}+\left(\frac{1}{4}-\frac{e}{2}+\frac{f}{4}\right)^{2} \\
& =\frac{1}{4}\left(1+(2 e-\sqrt{3} f)^{2}+4(\sqrt{3}-1) e f\right),
\end{aligned}
$$

which is greater than $1 / 4$ for $e, f>0$. Thus, equilibrium with perturbations of equal magnitudes but opposite signs for hiders and seekers can explain why central A is modal for both roles if $2 e+f>0$, but not its greater prevalence for seekers. It can explain the role-asymmetry in RTH's results only by invoking differences in the magnitudes of $e$ and $f$, with $2 e+f$ nearly twice as large for hiders as for seekers (Table 3, p. 1741). There is no logical reason why the game's roleasymmetric payoffs should not evoke instinctive reactions that differ this way, but neither to our knowledge is there any plausible theory to explain such differences. Without such a theory, perturbations of unrestricted magnitudes give the model enough flexibility to explain virtually any pattern of behavior, raising concerns about overfitting; and the lack of a theory also raises concerns about portability. (These issues are discussed in more detail in the Web Appendix.)

In RTH's unperturbed game, QRE coincides with equilibrium for any value of its precision parameter. But because QRE explains deviations from equilibrium in some other experiments, and it normally responds to payoff asymmetries, it is natural to hope that QRE with perturbations can explain RTH's results without unexplained differences in the magnitudes of the perturbations. ${ }^{7}$ We consider this possibility in the Web Appendix, focusing on the popular logit specification and assuming $e, f>0$ in Figure 2, which seems compelling. With perturbations of equal magnitudes, QRE, like equilibrium, can explain why central A is modal for hiders and seekers, but it robustly predicts that central A is more prevalent for hiders, the opposite of what RTH found. Perturbations of unrestricted magnitudes yield an effectively infinite estimate of QRE's precision parameter, reducing it to equilibrium with unrestricted perturbations. Thus, QRE is unhelpful in this setting.

\section{A Level- $k$ Model of RTH's Games}

This section introduces our proposed level- $k$ model for RTH's games and alternative level- $k$ models. Each player follows one of five types, $L 0, L 1, L 2, L 3$, or $L 4$, with given probabilities in each role $r, s, t, u$, and $v$. Type $L k$ for $k>0$ anchors its beliefs in type $L O$ and adjusts them via thought experiments with iterated best responses: $L 1$ best responds to $L O, L 2$ to $L 1$, and

\footnotetext{
${ }^{7}$ Rosenthal, Shachat, and Walker (2003) find that QRE gives a reasonable explanation of the qualitative features of subjects' role-asymmetric deviations from equilibrium in $2 \times 2$ hide-and-seek games with neutral framing but varying payoffs.
} 
so on. ${ }^{8}$ For $k>0$, these responses determine types' normal choices, with ties broken uniformly randomly.

For econometric reasons (see Section IV), we assume $r=0$, so the anchoring type $L O$ exists only in the minds of higher types, as the starting point for their strategic thinking. Even so, $L O$ is the key to the model's explanatory power. We also assume that $L O$ is payoff-insensitive as in most previous level- $k$ analyses; this choice is discussed below. In games with symmetric framing and sets of decisions like those we study, it is plausible to assume that a payoff-insensitive $L O$ is symmetric across player roles. ${ }^{9}$ We further assume that $L O$ probabilistically favors salient locations: B and the end As in RTH's games. Because the end $\mathrm{A}$ frequencies are almost equal in the data, we set their choice probabilities for $L O$ (and so for higher types) equal for simplicity. Thus, in RTH's games, $L O$ hiders and seekers both choose A, B, A, A with probabilities $p / 2, q$, $1-p-q, p / 2$, where $p>1 / 2$ and $q>1 / 4$.

When $r=0$, the model's implications apart from errors are determined by $L 1$ hiders' and seekers' best responses to $L O$, which determine the normal choices of $L 2, L 3$, and $L 4$, as well as $L 1$, and by the type frequencies $s, t, u$, and $v$. Table 2 lists types' normal choice probabilities when $p>1 / 2$ and $q>1 / 4$, distinguishing the cases $p<2 q$-in which $L O$ responds more strongly to the salience of a B than an end A location - and $p>2 q$. $L 1$ hiders choose central A to avoid $L O$ seekers, and $L 1$ seekers avoid central A in their searches for $L O$ hiders, choosing B if $p<2 q$ or the end As (with equal probabilities) if $p>2 q$. For similar reasons, $L 2$ hiders

\footnotetext{
${ }^{8}$ Costa-Gomes and Crawford (2006) summarize the experimental evidence for the level- $k$ model, and give support for our assumptions that $L 2$ best responds to an $L 1$ without decision errors, and to $L 1$ alone rather than a mixture of $L 1$ and $L O$, etc., unlike in Stahl and Wilson (1994, 1995) or (in the latter case) Camerer, Ho, and Chong (2004). In RTH's games, L5's choice probabilities (but not its expected payoffs) are the same as $L 1$ 's, so $L 5$ is equivalent to $L 1, L 6$ to $L 2$, and so on.

${ }^{9}$ One might argue that the framing isn't completely role-symmetric because the roles have different labels, but RTH's failure to find significant differences between the behavior of hiders in treasure treatments and seekers in mine treatments, and vice versa (Section I), suggests that role-asymmetric framing is not what is driving subjects' behavior.
}

choose central A with probability $1 / 3$ or $1 / 2$ and $L 2$ seekers choose it with probability $1 ; L 3$ hiders avoid central A and $L 3$ seekers choose it with probability $1 / 3$ or $1 / 2$; and $L 4$ hiders and seekers avoid central A. ${ }^{10}$

These choice patterns allow the model to explain RTH's results with behaviorally plausible type frequencies. Table 2's bottom lines give the population choice probabilities as functions of the type frequencies and the error rate $\varepsilon$. Section IV's econometric analysis (Table 3) confirms that a role-symmetric $L O$ with $p>2 q$ and a population with 19 percent $L 1,32$ percent $L 2,24$ percent $L 3$, and 25 percent $L 4$ players in each role closely matches RTH's hiders' and seekers' choice frequencies. This almost humpshaped type distribution is like those estimated for other settings (Stahl and Wilson 1994, 1995; Costa-Gomes, Crawford, and Broseta 2001; Camerer, Ho, and Chong 2004; Costa-Gomes and Crawford 2006). It is, however, shifted upward somewhat, perhaps due to the transparency of the strategic question hide-and-seek games pose. ${ }^{11}$

Imagine, more concretely, that in the situation of our first epigraph there are four meetings at which the government could try to poison Yushchenko. Meeting "B" is with government officials; but none of the others is salient the way RTH's end locations are. As the only salient location, B is the modal choice for $L O$ poisoners and investigators. $L 1$ poisoners avoid $\mathrm{B}$, but $L 1$ investigators choose it. $L 2$ poisoners and investigators both avoid B. L3 poisoners choose B, but $L 3$ investigators avoid it. $L 4$ poisoners and investigators both choose B. Thus, our first epigraph may reflect the reasoning of an $L 1$ poisoner, or equivalently of an $L 2$ investigator reasoning about an $L 1$ poisoner.

\footnotetext{
${ }^{10}$ These choices remain the same whenever $p+2 q>$ 1 and $3 p+2 q>2$; we maintain $p>1 / 2$ and $q>1 / 4$ for simplicity.

${ }^{11}$ This shift hints at the possibility of a more general theory that relates the type frequencies to the transparency and cognitive difficulty of the game. In contrast to RTH's interpretation of their results as evidence of strategic naïveté, using our level- $k$ model to explain their results implies lower bounds on the population's sophistication in that, for central A to be more prevalent for seekers than hiders, there must be sufficiently more $L 2$ and $L 3$ than $L 1$ subjects.
} 
Table 2-Types' Expected Payoffs and Choice Probabilities in RTH's Games when $p>1 / 2$ and $q>1 / 4$

\begin{tabular}{|c|c|c|c|c|c|c|c|c|c|}
\hline Hider & $\begin{array}{c}\text { Expected } \\
\text { payoff } \\
p<2 q\end{array}$ & $\begin{array}{c}\text { Choice } \\
\text { probability } \\
\quad p<2 q\end{array}$ & $\begin{array}{l}\text { Expected } \\
\text { payoff } \\
p>2 q\end{array}$ & $\begin{array}{c}\text { Choice } \\
\text { probability } \\
\quad p>2 q\end{array}$ & Seeker & $\begin{array}{c}\text { Expected } \\
\text { payoff } \\
p<2 q\end{array}$ & $\begin{array}{c}\text { Choice } \\
\text { probability } \\
p<2 q\end{array}$ & $\begin{array}{c}\text { Expected } \\
\text { payoff } \\
p>2 q\end{array}$ & $\begin{array}{c}\text { Choice } \\
\text { probability } \\
p>2 q\end{array}$ \\
\hline$L O($ Pr. $r)$ & & & & & $L O(\operatorname{Pr} . r)$ & & & & \\
\hline A & - & $p / 2$ & - & $p / 2$ & A & - & $p / 2$ & - & $p / 2$ \\
\hline B & - & $q$ & - & $q$ & $\mathrm{~B}$ & - & $q$ & - & $q$ \\
\hline A & - & $1-p-q$ & - & $1-p-q$ & A & - & $1-p-q$ & - & $1-p-q$ \\
\hline A & - & $p / 2$ & - & $p / 2$ & A & - & $p / 2$ & - & $p / 2$ \\
\hline$L 1($ Pr. $s)$ & & & & & $L 1(\operatorname{Pr} . s)$ & & & & \\
\hline A & $1-p / 2<3 / 4$ & 0 & $1-p / 2<3 / 4$ & 0 & A & $p / 2>1 / 4$ & 0 & $p / 2>1 / 4$ & $1 / 2$ \\
\hline B & $1-q<3 / 4$ & 0 & $1-q<3 / 4$ & 0 & $\mathrm{~B}$ & $q>1 / 4$ & 1 & $q>1 / 4$ & 0 \\
\hline A & $p+q>3 / 4$ & 1 & $p+q>3 / 4$ & 1 & A & $1-p-q<1 / 4$ & 0 & $1-p-q<1 / 4$ & 0 \\
\hline A & $1-p / 2<3 / 4$ & 0 & $1-p / 2<3 / 4$ & 0 & A & $p / 2>1 / 4$ & 0 & $p / 2>1 / 4$ & $1 / 2$ \\
\hline $\begin{array}{l}L 2(\operatorname{Pr} . t) \\
\mathrm{A}\end{array}$ & 1 & $1 / 3$ & $1 / 2$ & 0 & $\underset{\mathrm{A}}{L 2}(\operatorname{Pr} . t)$ & 0 & 0 & 0 & 0 \\
\hline B & 0 & 0 & 1 & $1 / 2$ & $\mathrm{~B}$ & 0 & 0 & 0 & 0 \\
\hline A & 1 & $1 / 3$ & 1 & $1 / 2$ & A & 1 & 1 & 1 & 1 \\
\hline A & 1 & $1 / 3$ & $1 / 2$ & 0 & A & 0 & 0 & 0 & 0 \\
\hline$L 3(\operatorname{Pr} . u)$ & & & & & $L 3(\operatorname{Pr} . u)$ & & & & \\
\hline A & 1 & $1 / 3$ & 1 & $1 / 3$ & A & $1 / 3$ & $1 / 3$ & 0 & 0 \\
\hline B & 1 & $1 / 3$ & 1 & $1 / 3$ & B & 0 & 0 & $1 / 2$ & $1 / 2$ \\
\hline A & 0 & 0 & 0 & 0 & $\mathrm{~A}$ & $1 / 3$ & $1 / 3$ & $1 / 2$ & $1 / 2$ \\
\hline A & 1 & $1 / 3$ & 1 & $1 / 3$ & A & $1 / 3$ & $1 / 3$ & 0 & 0 \\
\hline$L 4(\operatorname{Pr} . v)$ & & & & & $L 4(\operatorname{Pr} . v)$ & & & & \\
\hline A & $2 / 3$ & 0 & 1 & $1 / 2$ & A & $1 / 3$ & $1 / 3$ & $1 / 3$ & $1 / 3$ \\
\hline B & 1 & 1 & $1 / 2$ & 0 & $\mathrm{~B}$ & $1 / 3$ & $1 / 3$ & $1 / 3$ & $1 / 3$ \\
\hline A & $2 / 3$ & 0 & $1 / 2$ & 0 & A & 0 & 0 & 0 & 0 \\
\hline A & $2 / 3$ & 0 & 1 & $1 / 2$ & A & $1 / 3$ & $1 / 3$ & $1 / 3$ & $1 / 3$ \\
\hline Total & \multicolumn{2}{|c|}{$p<2 q$} & \multicolumn{2}{|c|}{$p>2 q$} & Total & \multicolumn{2}{|c|}{$p<2 q$} & \multicolumn{2}{|c|}{$p>2 q$} \\
\hline A & \multicolumn{2}{|c|}{$\begin{array}{c}r p / 2+(1-\varepsilon)[t / 3+u / 3] \\
+(1-r) \varepsilon / 4\end{array}$} & \multicolumn{2}{|c|}{$\begin{array}{c}r p / 2+(1-\varepsilon)[u / 3+v / 2] \\
+(1-r) \varepsilon / 4\end{array}$} & A & \multicolumn{2}{|c|}{$\begin{array}{c}r p / 2+(1-\varepsilon)[u / 3+v / 3] \\
+(1-r) \varepsilon / 4\end{array}$} & \multicolumn{2}{|c|}{$\begin{array}{c}r p / 2+(1-\varepsilon)[s / 2+v / 3] \\
+(1-r) \varepsilon / 4\end{array}$} \\
\hline B & \multicolumn{2}{|c|}{$\begin{array}{c}r q+(1-\varepsilon)[u / 3+v] \\
+(1-r) \varepsilon / 4\end{array}$} & \multicolumn{2}{|c|}{$\begin{array}{l}r q+(1-\varepsilon)[t / 2+u / 3] \\
\quad+(1-r) \varepsilon / 4\end{array}$} & B & \multicolumn{2}{|c|}{$\begin{array}{l}r q+(1-\varepsilon)[s+v / 3] \\
+(1-r) \varepsilon / 4\end{array}$} & \multicolumn{2}{|c|}{$\begin{array}{l}r q+(1-\varepsilon)[u / 2+v / 3] \\
+(1-r) \varepsilon / 4\end{array}$} \\
\hline A & \multicolumn{2}{|c|}{$\begin{array}{c}r(1-p-q)+(1-\varepsilon)[s+t / 3] \\
+(1-r) \varepsilon / 4\end{array}$} & \multicolumn{2}{|c|}{$\begin{array}{c}r(1-p-q)+(1-\varepsilon)[s+t / 2] \\
+(1-r) \varepsilon / 4\end{array}$} & A & \multicolumn{2}{|c|}{$\begin{array}{c}r(1-p-q)+(1-\varepsilon)[t+u / 3] \\
+(1-r) \varepsilon / 4\end{array}$} & \multicolumn{2}{|c|}{$\begin{array}{c}r(1-p-q)+(1-\varepsilon)[t+u / 2] \\
+(1-r) \varepsilon / 4\end{array}$} \\
\hline A & \multicolumn{2}{|c|}{$\begin{array}{c}r p / 2+(1-\varepsilon)[t / 3+u / 3] \\
+(1-r) \varepsilon / 4\end{array}$} & \multicolumn{2}{|c|}{$\begin{array}{c}r p / 2+(1-\varepsilon)[u / 3+v / 2] \\
+(1-r) \varepsilon / 4\end{array}$} & $\mathrm{~A}$ & \multicolumn{2}{|c|}{$\begin{array}{c}r p / 2+(1-\varepsilon)[u / 3+v / 3] \\
+(1-r) \varepsilon / 4\end{array}$} & \multicolumn{2}{|c|}{$\begin{array}{c}r p / 2+(1-\varepsilon)[s / 2+v / 3] \\
+(1-r) \varepsilon / 4\end{array}$} \\
\hline
\end{tabular}

The game referred to in our second epigraph, between a test-taker trying to guess the answer and a test-maker trying to minimize a guesser's chances, is exactly like RTH's games if location "c" is treated as equivalent to central A. Thus, our second epigraph may reflect the reasoning of an $L 1$ test-maker, or an $L 2$ guesser reasoning about an $L 1$ test-maker. Attali and BarHillel (2003) present intriguing field evidence on this game, from the Israeli analog of the US Scholastic Aptitude Test.
Like equilibrium with perturbations, our level- $k$ model is quite flexible, and the freedom to specify $L O$ makes it even more flexible. Our payoff-insensitive $L O$ assumes that a player processes the game's decisions and framing before its payoffs. We show in Section IV that two alternative level- $k$ models fit RTH's data slightly better than our proposed model: one that merges those processing steps as in Bacharach and Stahl's (1997a) payoff-sensitive, role-asymmetric $L O$ in which seekers favor salience and hiders 
avoid it; and one with a payoff-insensitive, rolesymmetric $L O$ that avoids salience. ${ }^{12}$ Section II's equilibrium with unrestricted perturbations model fits RTH's data best of all the models discussed here, but still only slightly better than our proposed model.

Despite our proposed model's slightly worse fit in RTH's dataset, we find its explanation of their results more convincing because its assumptions seem behaviorally more plausible and it does not rely on unexplained role differences in behavior or payoffs. To our knowledge, only a level$k$ model with a role-symmetric $L O$ can explain the robust patterns in RTH's data without unexplained differences in behavioral assumptions across roles. A payoff-insensitive $L O$ that avoids salience seems perverse, given that it responds only to decisions and framing. And a payoff-sensitive, role-asymmetric $L O$ suffers from the same overflexibility and lack of theory to guide its specification as equilibrium with perturbations. The analyses in Sections V and VI give support for these subjective judgments by showing that our proposed model has advantages in overfitting and portability. (These issues are discussed in more detail in the Web Appendix.)

\section{Econometric Analysis}

This section describes our econometric specification and then separately estimates the equilibrium with perturbations model and each possible level- $k$ model econometrically, using the pooled data from RTH's six treatments. We compare our proposed level- $k$ model, which has a rolesymmetric $L O$ that favors salience, with level- $k$ alternatives that relax the constraint that $L O$ is role-symmetric, that $L O$ favors salience, or both. Our goal is to illustrate the models' possibilities, not to take a definitive position on the behavioral

\footnotetext{
12 Bacharach and Stahl (1997a) analyze a simplified version of RTH's game with three locations, one clearly salient and one less clearly salient. They give an evolutionary justification for their role-asymmetric $L O$ : "For early humans, 'looking' problems were more generic and 'hiding' problems more strategic" (their footnote 13). Such a model can explain the main patterns in RTH's results with only types $L O, L 1$, and $L 2$, if there are more $L 2$ than $L O$ subjects. This type distribution seems lower and therefore closer to previous estimates than ours; but the difference is largely semantic because the behavior of their $L O$ is similar to that of our $L 1$, and their $L 1$ to that of our $L 2$, and so on.
}

parameters. Estimating the models rather than calibrating them constrains our discretion and yields likelihoods that provide an objective criterion by which to compare models.

Our econometric model is a mixture model as in Stahl and Wilson (1994, 1995) or CostaGomes, Crawford, and Broseta (2001), with one type for equilibrium with perturbations and up to four for the level- $k$ models. Let $X_{i j}$ be the total numbers of hiders or seekers (with $i=h, s$ ) who choose location $j$ (with $\mathrm{A}, \mathrm{B}, \mathrm{A}, \mathrm{A}$ denoted 1 , $2,3,4)$. Let $\pi_{k}$ be the probability that a given subject is type $k$, and $\rho_{i k j}$ be the probability that a hider or seeker of type $k$ chooses $j$. The fullsample likelihood can be written

$$
L \equiv \prod_{i=h, s} \prod_{j=1,2,3,4}\left[\sum_{k} \pi_{k} \rho_{i k j}\right]^{X_{i j}} .
$$

The equilibrium with perturbations models have $\rho_{i k j}$ as in Section II's analysis. Because the equilibrium that best fits RTH's results is totally mixed, errors would be redundant in this case. In the level- $k$ models, a player's type determines his normal choices as in Section III's analysis, with ties broken uniformly randomly, thus with $\rho_{i k j}$ as illustrated for our proposed model in Table 2. To avoid specification bias, we use the simplest possible error structure: with probability $\varepsilon$, a player makes an error, in which case he chooses his location uniformly randomly; errors are independent across players. The population choice probabilities are determined as functions of the behavioral parameters as in Table 2, with $\pi_{0}=r, \pi_{1}=s, \pi_{2}=t, \pi_{3}=u$, and $\pi_{4}=v$ in Section III's notation.

In the estimation, we rule out knife-edge $(p, q)$ combinations that make $L 1$ hiders or seekers indifferent between locations, because they implicitly allow $L 1$ to randomize, risking specification bias. ${ }^{13}$ We further constrain $r=0$. This constraint is not binding for our proposed model,

\footnotetext{
${ }^{13}$ We distinguish between ties that occur because two location choices are expected to yield the same outcome, which must be broken randomly in any consequentialist theory, and ties that exist only for knife-edge $(p, q)$ combinations. With a role-symmetric $L O$, the likelihood is occasionally maximized at such combinations because they make L1 randomize in a way that happens to fit the data better than our (deliberately naïve) error structure. We view such
} 
Table 3-Parameter Estimates and Likelihoods for the Leading Models in RTH's Games

\begin{tabular}{|c|c|c|c|c|c|c|c|c|}
\hline \multirow[t]{2}{*}{ Model } & \multirow[t]{2}{*}{ Ln L } & \multirow[t]{2}{*}{ Parameter estimates } & \multicolumn{5}{|c|}{ Observed or predicted choice frequencies } & \multirow[t]{2}{*}{ MSE } \\
\hline & & & Player & A & B & A & A & \\
\hline $\begin{array}{l}\text { Observed frequencies } \\
\text { (624 hiders, } 560 \text { seekers) }\end{array}$ & & & $\begin{array}{l}\mathrm{H} \\
\mathrm{S}\end{array}$ & $\begin{array}{l}0.2163 \\
0.1821\end{array}$ & $\begin{array}{l}0.2115 \\
0.2054\end{array}$ & $\begin{array}{l}0.3654 \\
0.4589\end{array}$ & $\begin{array}{l}0.2067 \\
0.1536\end{array}$ & - \\
\hline $\begin{array}{l}\text { Equilibrium without } \\
\text { perturbations }\end{array}$ & -1641.4 & & $\begin{array}{l}\mathrm{H} \\
\mathrm{S}\end{array}$ & $\begin{array}{l}0.2500 \\
0.2500\end{array}$ & $\begin{array}{l}0.2500 \\
0.2500\end{array}$ & $\begin{array}{l}0.2500 \\
0.2500\end{array}$ & $\begin{array}{l}0.2500 \\
0.2500\end{array}$ & 0.00970 \\
\hline $\begin{array}{l}\text { Equilibrium with } \\
\text { restricted perturbations }\end{array}$ & -1568.5 & $\begin{array}{l}e_{H} \equiv e_{S}=0.2187 \\
f_{H} \equiv f_{S}=0.2010\end{array}$ & $\begin{array}{l}\mathrm{H} \\
\mathrm{S}\end{array}$ & $\begin{array}{l}0.1897 \\
0.1897\end{array}$ & $\begin{array}{l}0.2085 \\
0.2085\end{array}$ & $\begin{array}{l}0.4122 \\
0.4122\end{array}$ & $\begin{array}{l}0.1897 \\
0.1897\end{array}$ & 0.00084 \\
\hline $\begin{array}{l}\text { Equilibrium with } \\
\text { unrestricted perturbations }\end{array}$ & -1562.4 & $\begin{aligned} e_{H} & =0.2910, f_{H}=0.2535 \\
e_{S} & =0.1539, f_{S}=0.1539\end{aligned}$ & $\begin{array}{l}\mathrm{H} \\
\mathrm{S}\end{array}$ & $\begin{array}{l}0.2115 \\
0.1679\end{array}$ & $\begin{array}{l}0.2115 \\
0.2054\end{array}$ & $\begin{array}{l}0.3654 \\
0.4590\end{array}$ & $\begin{array}{l}0.2115 \\
0.1679\end{array}$ & 0.00006 \\
\hline $\begin{array}{l}\text { Level- } k \text { with a } \\
\text { role-symmetric } \\
L O \text { that favors salience }\end{array}$ & -1564.4 & $\begin{array}{l}p>1 / 2 \text { and } q>1 / 4, p>2 q, \\
r=0, s=0.1896, t=0.3185 \\
u=0.2446, v=0.2473, \varepsilon=0\end{array}$ & $\begin{array}{l}\mathrm{H} \\
\mathrm{S}\end{array}$ & $\begin{array}{l}0.2052 \\
0.1772\end{array}$ & $\begin{array}{l}0.2408 \\
0.2047\end{array}$ & $\begin{array}{l}0.3488 \\
0.4408\end{array}$ & $\begin{array}{l}0.2052 \\
0.1772\end{array}$ & 0.00027 \\
\hline $\begin{array}{l}\text { Level- } k \text { with a role- } \\
\text { asymmetric } L O \text { that favors } \\
\text { salience for seekers } \\
\text { and avoids it for hiders }\end{array}$ & -1563.8 & $\begin{array}{c}p_{H}<1 / 2 \text { and } q_{H}<1 / 4 \\
p_{S}>1 / 2 \text { and } q_{S}>1 / 4 \\
r=0, s=0.66, t=0.34 \\
\varepsilon=0.72 ; u \equiv v \equiv 0 \text { imposed }\end{array}$ & $\begin{array}{l}\mathrm{H} \\
\mathrm{S}\end{array}$ & $\begin{array}{l}0.2117 \\
0.1800\end{array}$ & $\begin{array}{l}0.2117 \\
0.1800\end{array}$ & $\begin{array}{l}0.3648 \\
0.4600\end{array}$ & $\begin{array}{l}0.2117 \\
0.1800\end{array}$ & 0.00017 \\
\hline $\begin{array}{l}\text { Level- } k \text { with a } \\
\text { role-symmetric } \\
L O \text { that avoids salience }\end{array}$ & -1562.5 & $\begin{array}{c}p<1 / 2 \text { and } q<1 / 4, p<2 q \\
r=0, s=0.3636, t=0.0944 \\
u=0.3594, v=0.1826, \varepsilon=0\end{array}$ & $\begin{array}{l}\mathrm{H} \\
\mathrm{S}\end{array}$ & $\begin{array}{l}0.2133 \\
0.1670\end{array}$ & $\begin{array}{l}0.2112 \\
0.2111\end{array}$ & $\begin{array}{l}0.3623 \\
0.4549\end{array}$ & $\begin{array}{l}0.2133 \\
0.1670\end{array}$ & 0.00006 \\
\hline
\end{tabular}

but without it many of the alternative models have identification problems and those with a role-asymmetric $L O$ can achieve a near-perfect fit with $r=1$, "explaining" the data by tabulating them. ${ }^{14}$ Given $r=0$, estimating a level- $k$ model amounts to choosing the $(p, q)$ combination for $L O$, or equivalently the implied normal choices for $L 1$ seekers and hiders, such that the $L 1$ choices and the choices they imply for higher types maximize the likelihood, given the

maxima as spurious because it is implausible that there are very many subjects with such knife-edge combinations.

${ }^{14}$ We say only "near-perfect" because our models restrict $L O$ 's choice probabilities to be the same for end A locations within each player role, so their predicted frequencies are also the same, which is not quite true in the data. Equilibrium with perturbations imposes an analogous restriction, so this should not bias the comparisons. Without the $r=0$ constraint, all maximum-likelihood estimates for models with a role-asymmetric $L O$ are equivalent to $r=1$. Our proposed model estimates $r=0$ because, while a roleasymmetric $L O$ can fit hiders and seekers independently, a role-symmetric $L O$ cannot fit their different choices as well as higher types can. Our finding that there are no $L O$ subjects is consistent with the common finding that people underestimate others' sophistication relative to their own (Georg Weizsäcker 2003). restrictions imposed. Figure 3 graphs the regions in $(p, q)$-space for which $L O$ hiders or seekers yield each possible combination of choices for L1 hiders and seekers, numbered 1 through 6 . In the most general level- $k$ model, with no restriction on the role-symmetry of $L O$ or its response to salience, $L O$ hiders and seekers can be independently assigned to regions 1 through 6 , or equivalently (Figure 3) $L 1$ seekers' and hiders' choices can be chosen independently from fend As, central A, B , which yields 9 possible cases. ${ }^{15}$ With a role-symmetric L0 but no restriction on its response to salience, $L O$ hiders' and seekers' regions must be the same but can otherwise be chosen freely, which yields six possible cases. In our proposed model, with a role-symmetric $L O$ that favors salience, this joint choice is restricted to regions 1 and 2, in which $L 1$ hiders choose central A and $L 1$ seekers choose either B

\footnotetext{
15 The most general level- $k$ model falls short of full generality only because we define the types as discussed in footnote 8 , restrict $L O$ 's choice probabilities to be the same for end A locations within each player role, impose $r=0$, and rule out $(p, q)$ combinations that make $L 1$ hiders or seekers indifferent between locations.
} 


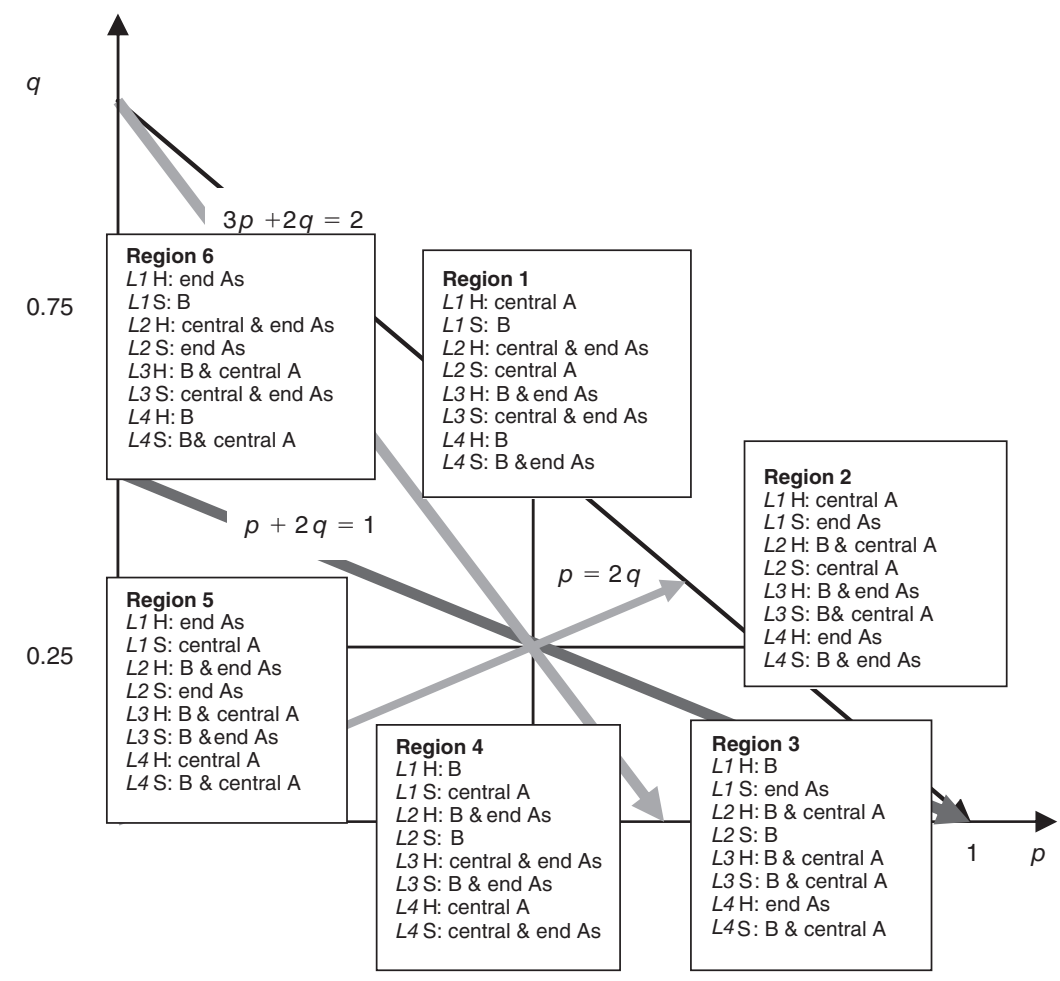

Figure 3. Ll's through L4's Choices in RTH's Games as Functions of LO's Choice

(region $1, p<2 q$ ) or end As (region 2, $p>2 q$ ). The $\rho_{i k j}$ in these regions can be read, for given type frequencies and error rate, from Table 2 with $r=0$; and the $\rho_{i k j}$ in other regions can be deduced from Figure $3 .{ }^{16}$

Table 3 summarizes the parameter estimates, likelihoods, and predicted choice frequencies for all models, with the observed frequencies for comparison. All the models are flexible enough to fit RTH's data very well. ${ }^{17}$ Equilibrium with

\footnotetext{
${ }^{16}$ If the regions defined by $p$ and $q$ for hiders and seekers are each viewed as a single, discrete parameter, the most general level- $k$ model has six independent parameters: a region each for hiders and seekers, three independent type frequencies, and an error rate. Restrictions on $L O$ 's response to salience do not affect this, while a restriction to a rolesymmetric $L O$ as in our proposed model reduces it to five. Equilibrium with unrestricted perturbations, with no error rate, has four parameters; and equilibrium with restricted perturbations has two.

${ }^{17}$ The likelihood gap is larger than it may appear, because the log-likelihood associated with perfect prediction of the
}

unrestricted perturbations fits best. Next best is a level- $k$ model with a role-symmetric $L O$ that avoids salience, with $L O$ hiders and seekers both in region 5. This model is equivalent when estimated to the most general level- $k$ model, with $L O$ hiders in region 4 or equivalently 5 and $L O$ seekers in region 6 or 5 . Next is a model with a roleasymmetric $L O$ with seekers favoring salience, in region 1 or 2 , and hiders avoiding it, in region 4 or 5 , as in Bacharach and Stahl (1997a). ${ }^{18}$ Next

choice frequencies is not 0 but -1561.7-negative because in these models even perfect prediction is only probabilistic.

${ }^{18}$ In this model, subscripts $H$ and $S$ distinguish $L O$ hiders' and seekers' choice probabilities. This model is unidentified even when $r=0$, because there are linear dependencies among types' choice probabilities that are the same for hiders and seekers. We report an estimate constraining $u=v$ $=0$ (ruling out $L 3$ and L4), following Bacharach and Stahl (1997a) in including only the lowest types, on the grounds that they are behaviorally more plausible. This choice has no substantive implications in RTH's dataset, but it matters in Section VI's analysis of portability. 
is our proposed model with a role-symmetric $L O$ that favors salience, with $L O$ hiders and seekers both in region 2 , which fits only slightly worse than the three previous models. Equilibrium with restricted perturbations fits worst of all. ${ }^{19}$

The estimated payoff perturbations in the equilibrium models have the expected positive signs, with unrestricted magnitudes nearly twice as large for hiders as for seekers. The estimated type distribution in our proposed level- $k$ model is behaviorally plausible, with the characteristic hump-shape of previous estimates but a shift toward higher, more sophisticated types (Section III). In this case, the restriction $r=0$ is nonbinding, so the model also reaffirms previous findings that $L O$ exists mainly in the minds of higher types. $L O$, in region 2 , responds more to the salience of an end A than a B location. As $\varepsilon=0$, types $L 1$ to $L 4$, taken together, explain the data better than uniform errors. ${ }^{20}$

The estimates for the alternative Bacharach and Stahl-style model, with a role-asymmetric $L O$ with seekers favoring salience and hiders avoiding it, are somewhat perverse, with plausible type frequencies but an error rate of $\varepsilon=0.72$, and identification problems even when $r=0$ (footnote 18 ).

The estimates for the best-fitting alternative level- $k$ model, with a role-symmetric $L O$ that avoids salience, are similar to those for our proposed model, again with $\varepsilon=0$ but with an implausible type distribution of 36 percent $L 1$, 9 percent $L 2,36$ percent $L 3$, and 18 percent L4 players, far from the typical hump shape. Ultimately, this alternative model will stand or fall on the plausibility of a payoff-insensitive $L O$ that avoids salience and on its overfitting and portability performance.

\footnotetext{
${ }^{19}$ We strongly reject the restrictions of equal magnitudes across roles ( $p$-value 0.0022). We focus below on equilibrium with unrestricted perturbations, which is equivalent in RTH's games to QRE with unrestricted perturbations.

${ }^{20}$ Without payoff perturbations, our uniform errors are perfectly confounded with the equilibrium mixed strategies. Thus $\varepsilon=0$ also suggests the absence of subjects who play equilibrium strategies, and it allows us to reject explanations in which some of the population choose locations with given probabilities (like $L O$ ), and the rest, like the Sophisticated type in Crawford (2003), play equilibrium in a game among themselves, taking those probabilities into account.
}

\section{Overfitting}

This section tests for overfitting by using each model to compute separate estimates for each of RTH's six treatments and using the reestimated models to "predict" the choice frequencies in the other five treatments. We evaluate the models by their MSEs.

Table 4 gives the MSEs, and Table A2 in the Web Appendix reports the estimates on which they are based. Even though our proposed level- $k$ model fits slightly worse than each alternative, it has a lower MSE than each alternative but the Bacharach and Stahl-style level- $k$ model with a role-asymmetric $L O$ with seekers favoring salience and hiders avoiding it, whose error is 10 percent lower.

\section{Portability}

This section takes up the issue of portability, the extent to which estimating the model for RTH's games helps to predict behavior in other games. We use each model, with the parameters estimated for RTH's games, to "predict" subjects' initial responses in the closest analogs of RTH's experiments we know of, O'Neill's (1987) card-matching experiment and Rapoport and Boebel's (1992) closely related experiment. (Their data for subjects' initial responses are included in our Data Appendix, available at http:// www.e-aer.org/data/dec07/20050133_data.zip, with permission.) Their games provide a good test of portability, raising the same strategic issues as RTH's games but with different framing, in one case five locations, and more complex win-loss patterns (Figures 4 and 5).

O'Neill, and Rapoport and Boebel, presented their games to subjects as stories, with locations ordered as in Figures 4 and 5. Rapoport and Boebel's subjects were also given a matrix like Figure 5, but with Ws or Ls for wins or losses. ${ }^{21}$

${ }^{21}$ O'Neill's story (2708) was: "Each player has four cards-Ace, two, three, and a joker .... [Player 1] wins if there is a match of jokers (two jokers played) or a mismatch of number cards (two, three, for example). [Player 2] wins if there is a match of number cards (three, three, for example) or a mismatch of a joker (one joker, one number card)." This wording leaves room for doubt whether Ace was also a "number" card, but his practice rounds made it clear to the subjects that it was. O'Neill had only one treatment, 
Table 4-MSEs Treatment by Treatment in RTH's Games

\begin{tabular}{|c|c|c|c|c|c|c|}
\hline \multirow[b]{2}{*}{ Estimated treatment } & \multicolumn{6}{|c|}{ Predicted treatment } \\
\hline & RTH-4 & $\begin{array}{c}\text { RT-AABA- } \\
\text { Treasure }\end{array}$ & $\begin{array}{l}\text { RT-AABA- } \\
\text { Mine }\end{array}$ & $\begin{array}{l}\text { RT-1234- } \\
\text { Treasure }\end{array}$ & $\begin{array}{c}\text { RT-1234- } \\
\text { Mine }\end{array}$ & R-ABAA \\
\hline \multicolumn{7}{|c|}{ Level- $k$ with symmetric $L O$ that favors salience: Overall MSE 0.00341} \\
\hline RTH-4 & 0.0020 & 0.0032 & 0.0098 & 0.0031 & 0.0019 & 0.0032 \\
\hline RT-AABA-Treasure & 0.0070 & 0.0014 & 0.0029 & 0.0011 & 0.0004 & 0.0048 \\
\hline RT-AABA-Mine & 0.0132 & 0.0042 & 0.0011 & 0.0029 & 0.0023 & 0.0085 \\
\hline RT-1234-Treasure & 0.0072 & 0.0016 & 0.0029 & 0.0007 & 0.0002 & 0.0037 \\
\hline RT-1234-Mine & 0.0054 & 0.0017 & 0.0035 & 0.0009 & 0.0000 & 0.0034 \\
\hline R-ABAA & 0.0040 & 0.0023 & 0.0073 & 0.0016 & 0.0010 & 0.0023 \\
\hline \multicolumn{7}{|c|}{ Equilibrium with unrestricted perturbations: Overall MSE 0.00418} \\
\hline RTH-4 & 0.0002 & 0.0088 & 0.0156 & 0.0079 & 0.0050 & 0.0087 \\
\hline RT-AABA-Treasure & 0.0089 & 0.0001 & 0.0039 & 0.0013 & 0.0017 & 0.0022 \\
\hline RT-AABA-Mine & 0.0153 & 0.0034 & 0.0005 & 0.0031 & 0.0032 & 0.0070 \\
\hline RT-1234-Treasure & 0.0076 & 0.0009 & 0.0031 & 0.0005 & 0.0004 & 0.0025 \\
\hline RT-1234-Mine & 0.0053 & 0.0018 & 0.0037 & 0.0009 & 0.0000 & 0.0036 \\
\hline R-ABAA & 0.0085 & 0.0019 & 0.0071 & 0.0027 & 0.0032 & 0.0004 \\
\hline \multicolumn{7}{|c|}{ Level- $k$ with symmetric $L O$ that avoids salience: Overall MSE 0.00359} \\
\hline RTH-4 & 0.0035 & 0.0062 & 0.0081 & 0.0050 & 0.0029 & 0.0054 \\
\hline RT-AABA-Treasure & 0.0091 & 0.0001 & 0.0040 & 0.0012 & 0.0018 & 0.0020 \\
\hline RT-AABA-Mine & 0.0148 & 0.0033 & 0.0005 & 0.0028 & 0.0029 & 0.0067 \\
\hline RT-1234-Treasure & 0.0069 & 0.0008 & 0.0028 & 0.0007 & 0.0003 & 0.0031 \\
\hline RT-1234-Mine & 0.0054 & 0.0017 & 0.0035 & 0.0010 & 0.0001 & 0.0041 \\
\hline R-ABAA & 0.0073 & 0.0008 & 0.0054 & 0.0021 & 0.0023 & 0.0010 \\
\hline \multicolumn{7}{|c|}{ Level- $k$ with asymmetric LO: Overall MSE 0.00306} \\
\hline RTH-4 & 0.0077 & 0.0016 & 0.0026 & 0.0009 & 0.0005 & 0.0025 \\
\hline RT-AABA-Treasure & 0.0086 & 0.0007 & 0.0038 & 0.0007 & 0.0010 & 0.0023 \\
\hline RT-AABA-Mine & 0.0085 & 0.0028 & 0.0017 & 0.0017 & 0.0007 & 0.0057 \\
\hline RT-1234-Treasure & 0.0081 & 0.0009 & 0.0029 & 0.0005 & 0.0005 & 0.0026 \\
\hline RT-1234-Mine & 0.0079 & 0.0014 & 0.0021 & 0.0007 & 0.0003 & 0.0034 \\
\hline R-ABAA & 0.0096 & 0.0024 & 0.0068 & 0.0025 & 0.0031 & 0.0006 \\
\hline
\end{tabular}

O'Neill's experiment had 25 subjects per role and Rapoport and Boebel's had 10. Subjects played the games repeatedly in fixed pairs, with feedback after each play. We focus on subjects' first-round choices, interpreting them as initial responses. ${ }^{22}$

while Rapoport and Boebel had two, which differed only in the scaling and expected magnitudes of payoffs in ways that do not affect the predictions of the theories considered here. There is a statistically significant difference between Rapoport and Boebel's treatments for player $2 \mathrm{~s}$ ( $p$-value 0.0087 ) but not for player 1s ( $p$-value 0.8557$)$. We keep their treatments separate in both player roles.

${ }^{22}$ Rapoport and Boebel's subjects played first in one player role, then the other. We use only a given subject's first response to the game, in either role. Even so, interpreting first-round choices as initial responses is less straightforward here than for RTH's subjects, who played a game only once or in a series without feedback, because with feedback it is theoretically possible for first-round choices to influence future play (even with random pairing, via
Tables 5 and 6 give the games' unique equilibrium mixed strategies and subjects' aggregate first-round choices. Equilibrium reflects the payoff-symmetry of actions A, 2, and 3 in O'Neill's game and of actions F, I, and $\mathrm{O}$ in Rapoport and Boebel's game. Equilibrium is also symmetric across player roles, as in RTH's games. We keep symmetric actions separate because equilibrium with perturbations and the level- $k$ models break the symmetries in response to differences in salience. Relative to equilibrium, O'Neill's subjects have a large, positive Joker ("J") effect for both players, with J even more prevalent for player 2s. ${ }^{23}$ Rapoport and Boebel's subjects have

\footnotetext{
"contagion"). Nonetheless, future influences do not seem to have been an important source of distortion in this case.

${ }^{23}$ Discussions of O'Neill's data have been dominated by a small, positive "Ace effect" when the data are aggregated
} 


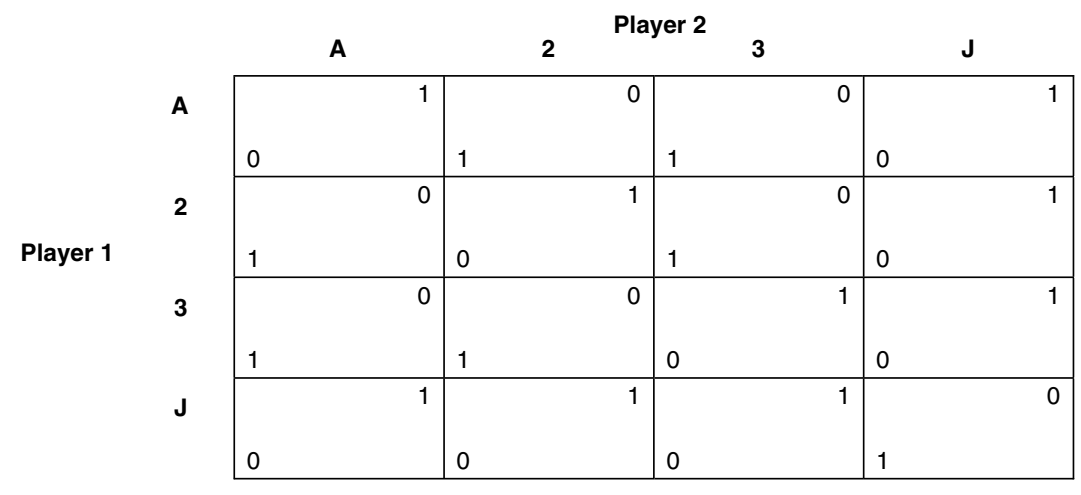

Figure 4. O'Neill's Card-Matching Game

Player 2

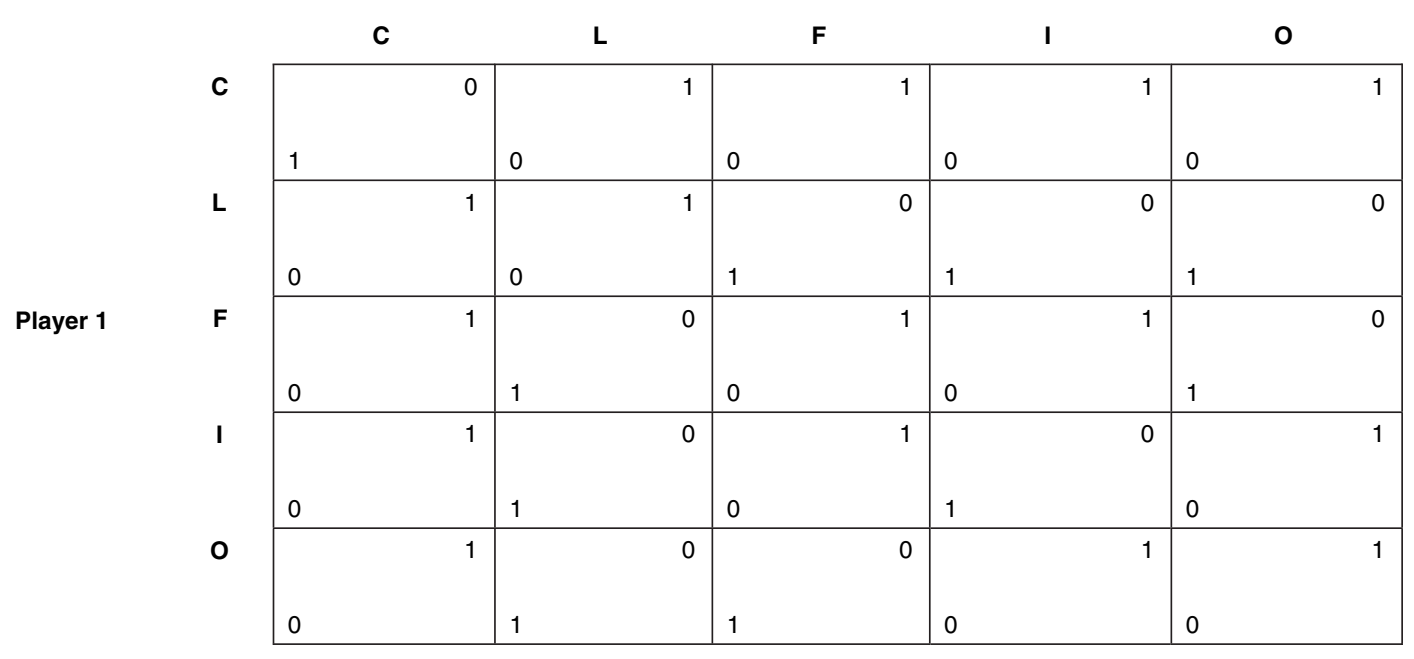

Figure 5. Rapoport and Boebel's Game

a large, positive I effect for player 1s in both treatments; a large, positive $\mathrm{C}$ effect for player

over all rounds (player 1s and 2s played A 22.0 percent and 22.6 percent of the time, versus the equilibrium 20 percent); see, for example, McKelvey and Palfrey (1995, 20). The Joker effect for initial responses, which is an order of magnitude larger, came as a surprise-a fortunate one for us because an Ace effect for player 1s is hard to square with a plausible level- $k$ model (Table A3 in the Web Appendix). Although O'Neill speculated that "players were attracted by the powerful connotations of an Ace," our analysis suggests that the aggregate Ace effect is due to learning, not salience.
$2 \mathrm{~s}$ in treatment 1 ; and a large, positive $\mathrm{L}$ effect for player $2 \mathrm{~s}$ in treatment $2 .{ }^{24}$

In adapting the equilibrium model's perturbations to O'Neill's and Rapoport and Boebel's games, we use the same general notions of salience and players' instinctive reactions to it as for RTH's games. Although O'Neill's game is not a hide-and-seek game, player 1 (row) can be viewed as a hider when he chooses one of

\footnotetext{
${ }^{24}$ We put less weight on Rapoport and Boebel's effects than on O'Neill's Joker effect because of Rapoport and Boebel's smaller sample sizes and the large differences in choice frequencies across their two treatments.
} 
Table 5-Comparison of the Leading Models in O'Neill's Game

\begin{tabular}{|c|c|c|c|c|c|c|c|}
\hline \multirow[t]{2}{*}{ Model } & \multirow[t]{2}{*}{ Parameter estimates } & \multicolumn{5}{|c|}{ Observed or predicted choice frequencies } & \multirow[t]{2}{*}{ MSE } \\
\hline & & Player & A & 2 & 3 & $\mathrm{~J}$ & \\
\hline \multirow{2}{*}{$\begin{array}{l}\text { Observed frequencies } \\
\text { (25 Player 1s, } 25 \text { Player } 2 \mathrm{~s})\end{array}$} & & 1 & 0.0800 & 0.2400 & 0.1200 & 0.5600 & - \\
\hline & & 2 & 0.1600 & 0.1200 & 0.0800 & 0.6400 & - \\
\hline \multirow{2}{*}{$\begin{array}{l}\text { Equilibrium without } \\
\text { perturbations }\end{array}$} & & 1 & 0.2000 & 0.2000 & 0.2000 & 0.4000 & 0.0120 \\
\hline & & 2 & 0.2000 & 0.2000 & 0.2000 & 0.4000 & 0.0200 \\
\hline \multirow{2}{*}{$\begin{array}{l}\text { Level- } k \text { with a role-symmetric } \\
\text { LO that favors salience }\end{array}$} & $a>1 / 4$ and $j>1 / 4$ & 1 & 0.0824 & 0.1772 & 0.1772 & 0.5631 & 0.0018 \\
\hline & $3 j-a<1, a+2 j<1$ & 2 & 0.1640 & 0.1640 & 0.1640 & 0.5081 & 0.0066 \\
\hline \multirow{2}{*}{$\begin{array}{l}\text { Level- } k \text { with a role-symmetric } \\
L O \text { that favors salience }\end{array}$} & $a>1 / 4$ and $j>1 / 4$ & 1 & 0.0000 & 0.2541 & 0.2541 & 0.4919 & 0.0073 \\
\hline & $3 j-a<1, a+2 j>1$ & 2 & 0.2720 & 0.0824 & 0.0824 & 0.5631 & 0.0050 \\
\hline \multirow{2}{*}{$\begin{array}{l}\text { Level- } k \text { with a role-symmetric } \\
L O \text { that avoids salience }\end{array}$} & $a<1 / 4$ and $j<1 / 4$ & 1 & 0.4245 & 0.1807 & 0.1807 & 0.2142 & 0.0614 \\
\hline & & 2 & 0.1670 & 0.1807 & 0.1807 & 0.4717 & 0.0105 \\
\hline \multirow{2}{*}{$\begin{array}{l}\text { Level- } k \text { with a role-asymmetric } L O \text { that } \\
\text { favors salience for locations for which } \\
\text { player is a seeker and avoids it for locations } \\
\text { for which player is a hider }\end{array}$} & $\begin{array}{c}a_{1}<1 / 4, j_{1}>1 / 4 \\
a_{2}>1 / 4, j_{2}<1 / 4\end{array}$ & 1 & 0.1804 & 0.2729 & 0.2729 & 0.2739 & 0.0291 \\
\hline & $\begin{array}{c}3 j_{1}-a_{1}<1 \\
a_{1}+2 j_{1}<1,3 a_{2}+j_{2}>1\end{array}$ & 2 & 0.1804 & 0.1804 & 0.1804 & 0.4589 & 0.0117 \\
\hline
\end{tabular}

the number cards A, 2, and 3 and a seeker when he chooses $\mathrm{J}$; and player 2 can be viewed as the reverse. The end positions of $\mathrm{A}$ and $\mathrm{J}$, and J's unique role in the payoff structure, reinforce the salience of their labels. We assume a player choosing a salient card for which he is a seeker receives an additional payoff of $\alpha$ for $\mathrm{A}$ and $\iota$ for $\mathrm{J}$; and one choosing a salient card for which he is a hider loses analogous payoffs (Figure 6). We constrain $\alpha, \iota \geq 0$, so players favor salient cards for which they are seekers and avoid salient cards for which they are hiders. We also allow $\alpha$ and $\iota$ to differ across roles, but we suppress this for ease of notation.

If $3 \alpha-\iota<1$ and $\alpha+3 \iota<2$, the perturbed O'Neill game has a unique, symmetric, totally mixed equilibrium in which player 1s and player 2 s both play $\mathrm{A}, 2,3$, and $\mathrm{J}$ with probabilities $(1-3 \alpha+\iota) / 5,(1+2 \alpha+\iota) / 5,(1+2 \alpha+\iota) / 5$, and $(2-\alpha-3 \iota) / 5$, with obvious changes if $\alpha$ and $\iota$ differ across roles. Either way, the probability of $\mathrm{J}$ is maximized subject to $\alpha, \iota \geq 0$ when $\alpha=$ $\iota=0$, which yields an equilibrium $\mathrm{J}$ probability of 0.4 , well below the observed frequency in each role. Thus, equilibrium with perturbations, even with new estimates of the perturbations for O'Neill's game, cannot explain his subjects' initial responses better than equilibrium without perturbations, which explains them poorly.
In adapting level- $k$ models to O'Neill's game, we define $L O$ using the same notions of salience and players' responses to it as for RTH's games, and the same estimated type frequencies. Thus, in our proposed model with a role-symmetric $L O$ that favors salience, $L O$ chooses $\mathrm{A}, 2,3, \mathrm{~J}$ with probabilities $a,(1-a-j) / 2,(1-a-j) / 2, j$ (treating 2 and 3 equally), where $a>1 / 4$ and $j$ $>1 / 4$. The model with a role-symmetric $L O$ that avoids salience is the same, but with $a<1 / 4$ and $j<1 / 4$. The Bacharach and Stahl-style model with a role-asymmetric $L O$ has $a_{1}<1 / 4$ and $j_{1}$ $>1 / 4$ for player $1 \mathrm{~s}$ (hiders when they choose $\mathrm{A}$, seekers when they choose $\mathrm{J}$ ) and $a_{2}>1 / 4$ and $j_{2}$ $<1 / 4$ for player $2 \mathrm{~s}^{25}$

\footnotetext{
${ }^{25}$ Our proposed model's choices remain the same whenever $3 a+j>1$, even if $a<1 / 4$ or $\mathrm{j}<1 / 4$, with similar relaxations for the alternative model with a role-symmetric $L O$ that avoids salience and the alternative Bacharach and Stahl-style model with a role-asymmetric $L O$ that favors salience for seekers but avoids it for hiders. Figure A3 in the Web Appendix, like Figure 3 for RTH's games, graphs the regions in $(a, j)$-space for which $L O$ yields each possible choice for $L 1$ player $2 \mathrm{~s}$ or $1 \mathrm{~s}$. For each model, we choose the region that is consistent with its constraints and that yields the best fit, given the type frequencies estimated for that model from RTH's data. In our proposed model, $a>1 / 4$ and $j>1 / 4$ (or the weaker condition $3 a+j>1$ ) restrict $L 1$ player 1 s and 2 s to one of three choice combinations: $\mathbf{J}$
} 
Table 6-Comparison of the Leading Models in Rapoport and Boebel's Game

\begin{tabular}{|c|c|c|c|c|c|c|c|c|c|}
\hline \multirow[t]{2}{*}{ Model } & \multirow{2}{*}{$\begin{array}{l}\text { Parameter } \\
\text { estimates }\end{array}$} & \multicolumn{6}{|c|}{ Observed or predicted choice frequencies } & \multirow{2}{*}{$\begin{array}{c}\text { MSE, } \\
\text { Tr. } 1 \\
\end{array}$} & \multirow{2}{*}{$\begin{array}{l}\text { MSE, } \\
\text { Tr. } 2 \\
\end{array}$} \\
\hline & & Player & $\mathrm{C}$ & $\mathrm{L}$ & $\mathrm{F}$ & I & $\mathrm{O}$ & & \\
\hline $\begin{array}{l}\text { Observed frequencies, Treatment } 1 \\
\quad(10 \text { Player } 1 \mathrm{~s}, 10 \text { Player } 2 \mathrm{~s})\end{array}$ & & $\begin{array}{l}1 \\
2\end{array}$ & $\begin{array}{l}0.1000 \\
0.8000\end{array}$ & $\begin{array}{l}0.0000 \\
0.0000\end{array}$ & $\begin{array}{l}0.2000 \\
0.0000\end{array}$ & $\begin{array}{l}0.6000 \\
0.1000\end{array}$ & $\begin{array}{l}0.1000 \\
0.1000\end{array}$ & $\begin{array}{l}- \\
-\end{array}$ & $\begin{array}{l}- \\
-\end{array}$ \\
\hline $\begin{array}{l}\text { Observed frequencies, Treatment } 2 \\
\quad(10 \text { Player } 1 \mathrm{~s}, 10 \text { Player } 2 \mathrm{~s})\end{array}$ & & $\begin{array}{l}1 \\
2\end{array}$ & $\begin{array}{l}0.1000 \\
0.2000\end{array}$ & $\begin{array}{l}0.1000 \\
0.6000\end{array}$ & $\begin{array}{l}0.1000 \\
0.2000\end{array}$ & $\begin{array}{l}0.6000 \\
0.0000\end{array}$ & $\begin{array}{l}0.1000 \\
0.0000\end{array}$ & $\begin{array}{l}- \\
-\end{array}$ & $\begin{array}{l}- \\
-\end{array}$ \\
\hline $\begin{array}{l}\text { Equilibrium without } \\
\text { perturbations }\end{array}$ & & $\begin{array}{l}1 \\
2\end{array}$ & $\begin{array}{l}0.3750 \\
0.3750\end{array}$ & $\begin{array}{l}0.2500 \\
0.2500\end{array}$ & $\begin{array}{l}0.1250 \\
0.1250\end{array}$ & $\begin{array}{l}0.1250 \\
0.1250\end{array}$ & $\begin{array}{l}0.1250 \\
0.1250\end{array}$ & $\begin{array}{l}0.0740 \\
0.0520\end{array}$ & $\begin{array}{l}0.0650 \\
0.0380\end{array}$ \\
\hline $\begin{array}{l}\text { Level- } k \text { with a role-symmetric } \\
L O \text { that favors salience }\end{array}$ & $\begin{array}{c}m>2 / 5, n>1 / 5 \\
3 m / 2+n>1\end{array}$ & $\begin{array}{l}1 \\
2\end{array}$ & $\begin{array}{l}0.3085 \\
0.4657\end{array}$ & $\begin{array}{l}0.3488 \\
0.1593\end{array}$ & $\begin{array}{l}0.0612 \\
0.0618\end{array}$ & $\begin{array}{l}0.2204 \\
0.2514\end{array}$ & $\begin{array}{l}0.0612 \\
0.0618\end{array}$ & $\begin{array}{l}0.0660 \\
0.0331\end{array}$ & $\begin{array}{l}0.0505 \\
0.0702\end{array}$ \\
\hline $\begin{array}{l}\text { Level- } k \text { with a role-symmetric } \\
L O \text { that favors salience }\end{array}$ & $\begin{array}{c}m>2 / 5, n>1 / 5 \\
3 m / 2+n<1\end{array}$ & $\begin{array}{l}1 \\
2\end{array}$ & $\begin{array}{l}0.3796 \\
0.4107\end{array}$ & $\begin{array}{l}0.4369 \\
0.2204\end{array}$ & $\begin{array}{l}0.0612 \\
0.1230\end{array}$ & $\begin{array}{l}0.0612 \\
0.1230\end{array}$ & $\begin{array}{l}0.0612 \\
0.1230\end{array}$ & $\begin{array}{l}0.1160 \\
0.0433\end{array}$ & $\begin{array}{l}0.0970 \\
0.0449\end{array}$ \\
\hline $\begin{array}{l}\text { Level- } k \text { with a role-symmetric } \\
L O \text { that avoids salience }\end{array}$ & $\begin{array}{c}m<2 / 5, n<1 / 5 \\
2 m+3 n<1\end{array}$ & $\begin{array}{l}1 \\
2\end{array}$ & $\begin{array}{l}0.0944 \\
0.4864\end{array}$ & $\begin{array}{l}0.5420 \\
0.1812\end{array}$ & $\begin{array}{c}0 \\
0.1213\end{array}$ & $\begin{array}{l}0.3636 \\
0.0898\end{array}$ & $\begin{array}{c}0 \\
0.1213\end{array}$ & $\begin{array}{l}0.0799 \\
0.0293\end{array}$ & $\begin{array}{l}0.0543 \\
0.0573\end{array}$ \\
\hline $\begin{array}{l}\text { Level- } k \text { with a role-symmetric } \\
L O \text { that avoids salience }\end{array}$ & $\begin{array}{c}m<2 / 5, n<1 / 5 \\
2 m+3 n>1\end{array}$ & $\begin{array}{l}1 \\
2\end{array}$ & $\begin{array}{l}0.1843 \\
0.4565\end{array}$ & $\begin{array}{l}0.5462 \\
0.1371\end{array}$ & $\begin{array}{l}0.0898 \\
0.1355\end{array}$ & $\begin{array}{l}0.0898 \\
0.1355\end{array}$ & $\begin{array}{l}0.0898 \\
0.1355\end{array}$ & $\begin{array}{l}0.1156 \\
0.0315\end{array}$ & $\begin{array}{l}0.0933 \\
0.0642\end{array}$ \\
\hline
\end{tabular}

Table 5 summarizes the observed choice frequencies and the alternative models' predicted frequencies and MSEs for O'Neill's game, with equilibrium (without perturbations) as the bestfitting equilibrium model, and using Table 3's RTH estimates of $s, t, u, v$, and $\varepsilon$ for the level- $k$ models. ${ }^{26}$ Our proposed level- $k$ model with a rolesymmetric $L O$ that favors salience has lower MSE than any of the alternatives. This model makes J modal for player $1 \mathrm{~s}$ and $2 \mathrm{~s}$ and in one case reproduces its greater prevalence for $2 \mathrm{~s}$, so the same behavioral assumptions we used to explain the prevalence of central A and its greater prevalence for seekers in RTH's experiments explain O'Neill's Joker effect.

\footnotetext{
for player $1 \mathrm{~s}$ and A for player $2 \mathrm{~s}($ when $3 j-a>1) ; 2,3$ for player $1 \mathrm{~s}$ and A for player $2 \mathrm{~s}$ (when $3 j-a<1$ and $a+2 j$ $>1$ ); or 2,3 for player $1 \mathrm{~s}$ and $\mathrm{J}$ for player $2 \mathrm{~s}$ (when $a+2 j$ $<1$, which given $3 a+j>1$ implies $3 j-a<1$ ). In the model with a role-symmetric $L O$ that avoids salience, $L 1$ player $1 \mathrm{~s}$ and $2 \mathrm{~s}$ are similarly restricted to A for player $1 \mathrm{~s}$ and $\mathrm{J}$ for player $2 \mathrm{~s}$. In the Bacharach and Stahl-style model, L1 player 1s' and 2s' choices can be chosen independently from $\{\mathrm{A} ; 2,3\}$ for player $1 \mathrm{~s}$ and $\{\mathrm{A} ; 2,3 ; \mathrm{J}\}$ for player $2 \mathrm{~s}$.

${ }^{26}$ Tables A3 and A4 in the Web Appendix, like Table 2 for RTH's games, give types' expected payoffs and choice probabilities for our proposed model in O'Neill's game in the leading regions.
}

Adapting the equilibrium with perturbations model to Rapoport and Boebel's game raises new difficulties. Although their game is very close in structure to the games of RTH and O'Neill games, it no longer makes a player unambiguously a hider or seeker for all choices, and so allows no plausible, parsimonious parameterization of perturbations. ${ }^{27}$ We could use a more flexible parameterization and just "let the data speak." But this would take us farther from the general notions of instinctive reactions to salience we used to adapt the perturbations from RTH's to O'Neill's game, and even a parameterization as tight as we used for those games tends to overfit (Section V). The prospects for a useful equilibrium with perturbations analysis of Rapoport and Boebel's results seem dim.

In adapting level- $k$ models to Rapoport and Boebel's game, we assume that their $20 \mathrm{~s}$ respond to salience qualitatively as in RTH's and O'Neill's games. We assume that the abstract labels C, L, F, I, O are not salient per se, but

\footnotetext{
${ }^{27}$ Player 1 (2) is a seeker (hider) for location C. When C is eliminated, player 1 (2) is a hider (seeker) for location L. But even when $\mathrm{L}$ and $\mathrm{C}$ are eliminated, the player roles for location $\mathrm{F}$ cannot be classified this way.
} 


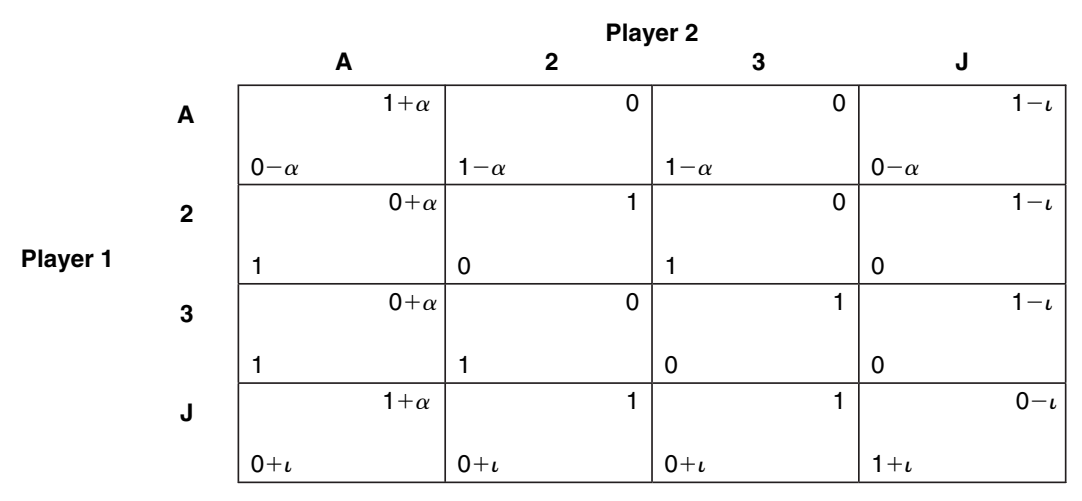

Figure 6. O’Neill's Card-Matching Game with Payoff Perturbations

that the end and center locations are inherently salient (Attali and Bar-Hillel 2004). Thus, in our proposed model with a role-symmetric $L O$ that favors salience, $L O$ player $1 \mathrm{~s}$ and $2 \mathrm{~s}$ both choose $\mathrm{C}, \mathrm{L}, \mathrm{F}, \mathrm{I}, \mathrm{O}$ with probabilities $m / 2,(1-m-n) / 2$, $n,(1-m-n) / 2, m / 2$ (again treating end locations equally), with $m>2 / 5$ and $n>1 / 5$. The alternative model with a role-symmetric $L O$ that avoids salience is the same, but with $m<2 / 5$ and $n$ $<1 / 5{ }^{28}$ However, specifying a Bacharach and Stahl-style model with a payoff-sensitive, roleasymmetric $L O$ raises difficulties like those for equilibrium with perturbations, in that there are no natural restrictions on $m$ and $n$.

Table 6 summarizes the observed choice frequencies and the alternative models' predicted frequencies and MSEs for Rapoport and Boebel's game, with equilibrium (without perturbations) as the best-fitting equilibrium model, and using Table 3's estimates of $s, t, u, v$, and $\varepsilon$ for the level- $k$ models, choosing among regions as for O'Neill's game (footnote 25). None of the models fits well, which may reflect the large variation in player $2 s^{\prime}$ frequencies of $\mathrm{C}$ and $\mathrm{L}$ across their treatments. Our proposed level- $k$ model has MSEs lower than equilibrium and the level- $k$ model that avoids salience except for player $2 \mathrm{~s}$ in treatment 2 , which are best captured

\footnotetext{
${ }^{28}$ In each case, $L 1$ player $1 \mathrm{~s}^{\prime}$ and $2 \mathrm{~s}^{\prime}$ choices remain the same under weaker conditions. Table A5 in the Web Appendix gives types' expected payoffs and choice probabilities for our proposed model in Rapoport and Boebel's game in the leading regions.
}

by equilibrium. Our proposed model reproduces a small fraction of the I effect for player 1s in both treatments and the $\mathrm{C}$ effect for player $2 \mathrm{~s}$ in treatment 1 , but it completely misses the $\mathrm{L}$ effect for player $2 \mathrm{~s}$ in treatment 2 .

\section{Conclusion}

This paper has compared alternative explanations of the systematic deviations from equilibrium in RTH's experiments with hide-and-seek games with nonneutral framing of locations, and in O'Neill's and Rapoport and Boebel's experiments with closely related games. Our analysis explores the issues that arise in specifying level- $k$ and alternative models for games played on nonneutral landscapes. It then shows that a structural nonequilibrium model of initial responses based on "level- $k$ " thinking, with a payoff-insensitive anchoring $L O$ type, can explain RTH's results, including their puzzling role-asymmetries, without assuming differences in behavior across roles.

Our proposed model fits RTH's data slightly worse than some of the alternatives, but we find its explanation of their results more convincing because its assumptions seem behaviorally more plausible and it (alone) does not rely on unexplained role differences in behavior or payoffs. Our analyses of overfitting and portability give support for these subjective judgments. They also trace the model's advantages to two features. First, it is based on general decision rules or "types" that apply to any game, whose population frequencies tend to be stable across 
different games. Second, its $L O$ is based on simple principles-how salience is determined by the set of decisions and their framing, and how people respond to it-for which there is strong support, whose simplicity facilitates transfer to new games, just as the sensitivity to the details of the structure of alternative specifications of $L O$ or the payoff perturbations in an equilibrium model inhibit transfer.

\section{REFERENCES}

Attali, Yigal, and Maya Bar-Hillel. 2003. "Guess Where: The Position of Correct Answers in Multiple-Choice Test Items as a Psychometric Variable." Journal of Educational Measurement, 40(2): 109-28.

Bacharach, Michael, and Dale O. Stahl. 1997a. "Variable-Frame Level- $n$ Theory." http://www. eco.utexas.edu/ stahl/vflnt4a.pdf.

Bacharach, Michael, and Dale O. Stahl. 1997b. "Variable-Frame Level- $n$ Theory with Application to Hide and Seek." Institute of Economics and Statistics, University of Oxford Working Paper.

- Bacharach, Michael, and Dale O. Stahl. 2000. "Variable-Frame Level- $n$ Theory." Games and Economic Behavior, 32(2): 220-46.

Bardsley, Nicholas, Judith Mehta, Chris Starmer, and Robert Sugden. 2006. "The Nature of Salience Revisited: Cognitive Hierarchy Theory versus Team Reasoning." Centre for Decision Research and Experimental Economics Discussion Paper 2006-17.

- Camerer, Colin F., Teck-Hua Ho, and Juin-Kuan Chong. 2004. "A Cognitive Hierarchy Model of Games." Quarterly Journal of Economics, 119(3): 861-98.

Chivers, C. J. 2004. "A Dinner in Ukraine Made for Agatha Christie." New York Times, December 20, A1.

Christenfeld, Nicholas. 1995. "Choices from Identical Options.” Psychological Science, 6(1): $50-55$.

Costa-Gomes, Miguel A., and Vincent P. Crawford. 2006. "Cognition and Behavior in TwoPerson Guessing Games: An Experimental Study." American Economic Review, 96(5): 1737-68.

Costa-Gomes, Miguel A., Vincent P. Crawford, and Bruno Broseta. 2001. "Cognition and
Behavior in Normal-Form Games: An Experimental Study." Econometrica, 69(5): 11931235.

Crawford, Vincent. 2003. "Lying for Strategic Advantage: Rational and Boundedly Rational Misrepresentation of Intentions." American Economic Review, 93(1): 133-49.

Crawford, Vincent, Uri Gneezy, and Yuval Rottenstreich. 2007. "The Power of Focal Points Is Limited: Even Minute Payoff Asymmetry May Yield Large Coordination Failures." Unpublished.

Crawford, Vincent P., and Nagore Iriberri. 2007. "Level-k Auctions: Can a Non-Equilibrium Model of Strategic Thinking Explain the Winner's Curse and Overbidding in Private-Value Auctions?" Econometrica, 75(6): 1721-70.

Ho, Teck-Hua, Colin Camerer, and Keith Weigelt. 1998. "Iterated Dominance and Iterated Best Response in Experimental 'p-Beauty Contests." American Economic Review, 88(4): 947-69.

Keillor, Garrison. 1997. Wobegon Boy. New York: Viking Press.

McKelvey, Richard, and Thomas Palfrey. 1995. "Quantal Response Equilibria for NormalForm Games." Games and Economic Behavior, 10(1): 6-38.

Mehta, Judith, Chris Starmer, and Robert Sugden. 1994. "The Nature of Salience: An Experimental Investigation of Pure Coordination Games." American Economic Review, 84(3): 658-73.

Nagel, Rosemarie. 1995. "Unraveling in Guessing Games: An Experimental Study." American Economic Review, 85(5): 1313-26.

von Neumann, John. 1953. "A Certain Zero-Sum Two-Person Game Equivalent to the Optimal Assignment Problem," In Contributions to the Theory of Games, Vol. II, ed. Harold W. Kuhn and Albert W. Tucker, 5-12. Princeton: Princeton University Press.

O'Neill, Barry. 1987. "Nonmetric Test of the Minimax Theory of Two-Person Zerosum Games." Proceedings of the National Academy of Sciences of the United States of America, 84(7): 2106-09.

Rapoport, Amnon, and Richard B. Boebel. 1992. "Mixed Strategies in Strictly Competitive Games: A Further Test of the Minimax Hypothesis." Games and Economic Behavior, 4(2): 261-83. 
- Rosenthal, Robert W., Jason Shachat, and Mark Walker. 2003. "Hide and Seek in Arizona." International Journal of Game Theory, 32(2): 273-93.

Rubinstein, Ariel. 1999. "Experience from a Course in Game Theory: Pre and Post-Class Problem Sets as a Didactic Device." Games and Economic Behavior, 28(1): 155-70.

Rubinstein, Ariel. 1999 (revised). "Experience from a Course in Game Theory: Pre and PostClass Problem Sets as a Didactic Device." http://arielrubinstein.tau.ac.il/99/gt100.html.

Rubinstein, Ariel, and Amos Tversky. 1993. "Naïve Strategies in Zero-Sum Games." Sackler Institute of Economic Studies, Tel Aviv University Working Paper 17-93.

Rubinstein, Ariel, Amos Tversky, and Dana Heller. 1996. "Naïve Strategies in Competitive Games," In Understanding Strategic Interaction-Essays in Honor of Reinhard Selten, ed. Wulf Albers, Werner Güth, Peter Ham- merstein, Bemmy Moldovanu, and Eric van Damme, 394-402. Berlin: Springer-Verlag.

- Scharlemann, Jörn, Catherine Eckel, Alex Kacelnik, and Rick Wilson. 2001. "The Value of a Smile: Game Theory with a Human Face." Journal of Economic Psychology, 22(5): 617-40.

Schelling, Thomas C. 1960. The Strategy of Conflict. Cambridge, MA: Harvard University Press.

-Stahl, Dale O., and Paul W. Wilson. 1994. "Experimental Evidence on Players' Models of Other Players." Journal of Economic Behavior and Organization, 25(3): 309-27.

-Stahl, Dale O., and Paul W. Wilson. 1995. "On Players' Models of Other Players: Theory and Experimental Evidence." Games and Economic Behavior, 10(1): 218-54.

Weizsäcker, Georg. 2003. "Ignoring the Rationality of Others: Evidence from Experimental Normal-Form Games." Games and Economic Behavior, 44(1): 145-71. 